Louisiana State University

LSU Digital Commons

$9-11-2017$

\title{
Effects of Pectin Molecular Weight Changes on the Structure, Dynamics, and Polysaccharide Interactions of Primary Cell Walls of Arabidopsis thaliana: Insights from Solid-State NMR
}

\author{
Pyae Phyo \\ Massachusetts Institute of Technology \\ Tuo Wang \\ Massachusetts Institute of Technology \\ Chaowen Xiao \\ Pennsylvania State University \\ Charles T. Anderson \\ Pennsylvania State University \\ Mei Hong \\ Massachusetts Institute of Technology
}

Follow this and additional works at: https://digitalcommons.Isu.edu/chemistry_pubs

\section{Recommended Citation}

Phyo, P., Wang, T., Xiao, C., Anderson, C., \& Hong, M. (2017). Effects of Pectin Molecular Weight Changes on the Structure, Dynamics, and Polysaccharide Interactions of Primary Cell Walls of Arabidopsis thaliana: Insights from Solid-State NMR. Biomacromolecules, 18 (9), 2937-2950. https://doi.org/10.1021/ acs.biomac. 7 b00888

This Article is brought to you for free and open access by the Department of Chemistry at LSU Digital Commons. It has been accepted for inclusion in Faculty Publications by an authorized administrator of LSU Digital Commons. For more information, please contact ir@lsu.edu. 


\section{MIT}

\section{Effects of Pectin Molecular Weight Changes on the Structure, Dynamics, and Polysaccharide Interactions of Primary Cell Walls of}

The MIT Faculty has made this article openly available. Please share how this access benefits you. Your story matters.

Citation

Phyo, Pyae et al. "Effects of Pectin Molecular Weight Changes on the Structure, Dynamics, and Polysaccharide Interactions of Primary Cell Walls of Arabidopsis Thaliana: Insights from SolidState NMR." Biomacromolecules 18, 9 (August 2017): 2937-2950 @ 2017 American Chemical Society

As Published

http://dx.doi.org/10.1021/acs.biomac.7b00888

Publisher

American Chemical Society (ACS)

Version

Author's final manuscript

Citable link

http://hdl.handle.net/1721.1/117388

Terms of Use

Article is made available in accordance with the publisher's policy and may be subject to US copyright law. Please refer to the publisher's site for terms of use. 


\title{
Effects of Pectin Molecular-Weight Changes on the
}

\author{
Structure, Dynamics, and Polysaccharide
}

\section{Interactions of Primary Cell Walls of Arabidopsis}

\section{thaliana: Insights from Solid-State NMR}

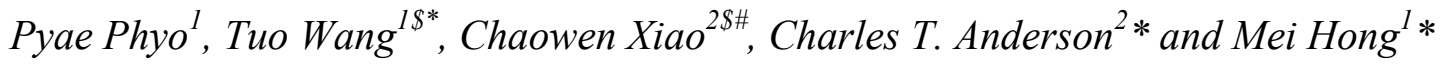 \\ ${ }^{1}$ Department of Chemistry, Massachusetts Institute of Technology, 170 Albany Street, \\ Cambridge, MA 02139 \\ ${ }^{2}$ Department of Biology, Pennsylvania State University, University Park, PA 16802 \\ $\$$ These authors contributed equally to this work. \\ * Present address: Department of Chemistry, Louisiana State University, Baton Rouge, LA 70809 \\ ${ }^{\#}$ Present address: College of Life Sciences, Sichuan University, Chengdu, China
}

Revised for Biomacromolecules

August 2, 2017 


\begin{abstract}
Significant cellulose-pectin interactions in plant cell walls have been reported recently based on $2 \mathrm{D}{ }^{13} \mathrm{C}$ solid-state NMR spectra of intact cell walls, but how these interactions affect cell growth has not been probed. Here, we characterize two Arabidopsis thaliana lines with altered expression of a PGXI (POLYGALACTURONASE INVOLVED IN EXPANSION1) gene, which encodes a polygalacturonase that cleaves homogalacturonan (HG). $P G X 1^{A T}$ plants overexpress $P G X 1$, have $\mathrm{HG}$ with lower molecular weight and grow larger, whereas pgx 1-2 knockout plants have HG with higher molecular weight and grow smaller. Quantitative ${ }^{13} \mathrm{C}$ solidstate NMR spectra show that $P G X 1^{A T}$ cell walls have lower galacturonic acid and xylose contents and higher HG methyl esterification than controls, whereas high molecular-weight pgxl-2 walls have similar galacturonic acid content and methyl esterification as controls. ${ }^{1} \mathrm{H}$-transferred ${ }^{13} \mathrm{C}$ INEPT spectra indicate that the interfibrillar HG backbones are more aggregated while the RG-I sidechains are more dispersed in $P G X 1^{A T}$ cell walls than in $p g x 1-2$ walls. In contrast, the pectins that are close to cellulose become more mobile and have weaker cross peaks with cellulose in $P G X 1^{A T}$ walls than in $p g x 1-2$ walls. Together, these results show that polygalacturonasemediated plant growth is accompanied by increased esterification and decreased crosslinking of $\mathrm{HG}$, increased aggregation of interfibrillar $\mathrm{HG}$, and weaker HG-cellulose interactions. These structural and dynamical differences give molecular insights into how pectins influence wall dynamics during cell growth.
\end{abstract}




\author{
Abbreviations: \\ Ara, A, arabinose; \\ CW, cell wall; \\ $\mathrm{CP}$, cross polarization; \\ DP, direct polarization; \\ Gal, Galactose; \\ GalA, GA, galacturonic acid; \\ HG, homogalacturonan; \\ INEPT, insensitive nuclei enhanced by polarization transfer; \\ MAS, magic-angle spinning; \\ PDSD, proton-driven ${ }^{13} \mathrm{C}-{ }^{13} \mathrm{C}$ spin diffusion, \\ SSNMR, solid-state nuclear magnetic resonance; \\ MW, molecular weight; \\ PGX1, POLYGALACTURONASE INVOLVED IN EXPANSION1; \\ RG-I, rhamnogalacturonan I; \\ Rha, R; rhamnose; \\ XyG, xyloglucan; \\ Xyl, x, xylose.




\section{Introduction}

Plant cell walls are composed of interconnected networks of polysaccharides that include cellulose, hemicelluloses, and pectins. Cellulose contains multiple $\beta$-(1,4)-glucan chains that are hydrogen-bonded in parallel to form microfibrils in plants ${ }^{1,2}$. Hemicelluloses differ between primary and secondary cell walls and between different plant taxa ${ }^{3}$. The main hemicellulose in the primary walls of eudicots is xyloglucan (XyG), whereas hemicelluloses in the primary walls of commelinoid monocots consist largely of glucuronoarabinoxylan (GAX) and mixed-linkage glucans ${ }^{3,4}$. Hemicelluloses have been hypothesized to interact strongly with cellulose and serve as mechanical tethers or adhesives between cellulose microfibrils ${ }^{5-7}$.

While cellulose and hemicelluloses are neutral polymers, pectins are acidic polysaccharides with or without sidechains ${ }^{8,9}$. Homogalacturonan (HG) is a linear homopolymer of $\alpha$-(1,4)-linked galacturonic acid (GalA), whose C6 carboxyl is often esterified upon HG delivery to the cell wall. These methyl esters can be subsequently removed by pectin methylesterases, enabling pairs of carboxyl groups on two HG chains to coordinate calcium ions and form inter-chain crosslinks, stiffening the wall ${ }^{10}$. Thus, the degree of HG esterification impacts the biomechanical properties of cell walls. However, the exact relationships between HG esterification, calcium-crosslinked network formation, wall extensibility, and cell growth are not well understood ${ }^{10,11}$. For example, although calcium crosslinking of de-esterified HG chains would be expected to rigidify the cell wall and constrain cell growth, de-esterification has been reported to correlate with wall weakening and increased cell expansion ${ }^{10,12,13}$. This suggests that de-esterified $\mathrm{HG}$ might be more susceptible to pectin-degrading enzymes such as polygalacturonases, which hydrolyze $\mathrm{HG}$, or pectate lyases, which cleave $\mathrm{HG}$ via $\beta$-elimination ${ }^{8}$. The second major pectin in primary cell walls is rhamnogalacturonan I (RG-I), which contains a backbone with alternating rhamnose (Rha) and GalA units and neutral sidechains that consist of 
arabinan, galactan and arabinogalactan ${ }^{14,15}$. RG-I side chains have been hypothesized to mediate pectin interactions with cellulose ${ }^{16}$. The third type of pectin is rhamnogalacturonan II, which contains an HG backbone decorated with multiple complex side chains and can be crosslinked via borate diesters ${ }^{14}$.

For decades, the three-dimensional structures of plant cell walls have been difficult to determine due to the insoluble and heterogeneous nature of cell walls. As a result, it is not well understood how cellulose and matrix polysaccharides interact non-covalently to allow the formation of a strong but extensible network for plant cell stability and growth. Earlier models of eudicot primary walls hypothesized that XyG coats the surface of cellulose microfibrils and tethers them into a load-bearing network, which is embedded in a second phase formed by wellhydrated pectins $6,7,17,18$. However, recent biochemical and biomechanical measurements and solid-state NMR data suggest an alternative model in which $\mathrm{XyG}$ is entrapped at a limited number of sites between cellulose microfibrils to regulate wall loosening ${ }^{19-21}$. This biomechanical hotspot model is manifested in terms of a limited number of XyG-cellulose cross peaks in $2 \mathrm{D}$ and $3 \mathrm{D}{ }^{13} \mathrm{C}$ correlation NMR spectra, binding of the wall-loosening protein, $\alpha$ expansin, to XyG-enriched region of the cellulose microfibril ${ }^{22,23}$, and changes in cellulose microfibril synthesis and organization in the XyG-deficient $x x t 1 x x t 2$ mutant $^{24}$.

We have recently employed ${ }^{13} \mathrm{C}$-enriched whole plants and multidimensional ${ }^{13} \mathrm{C}$ correlation solid-state NMR spectroscopy to investigate the structure and dynamics of polysaccharides in intact primary cell walls. Eudicot and commelinid monocot plants, including Arabidopsis thaliana, Brachypodium distachyon, and Zea mays, have been studied ${ }^{25,26}$. In eudicot cell walls, intermolecular cross peaks in $2 \mathrm{D}$ and $3 \mathrm{D}{ }^{13} \mathrm{C}$ correlation spectra indicated that cellulose microfibrils are within a nanometer of both pectins and $\mathrm{XyG}$, thus the three major polymers form a single interconnected network ${ }^{22,27}$. In particular, a significant number of 
cellulose-HG and cellulose-RG I cross peaks were observed, indicating that cellulose and pectins interact on the sub-nanometer scale ${ }^{28,29} \cdot{ }^{13} \mathrm{C}$ spin-lattice relaxation times $\left(\mathrm{T}_{1}\right)$ and ${ }^{1} \mathrm{H}$ rotatingframe spin-lattice relaxation times $\left(T_{1 \rho}\right)$ show a bimodal distribution of relaxation times for pectins, indicating that pectin backbones have a mobile domain and a rigid domain, which may correspond to segments that reside between cellulose microfibrils and segments that interact with cellulose, respectively ${ }^{28}$. Removal of calcium-crosslinked HG decreased the amount of bound water and slowed down water ${ }^{1} \mathrm{H}$ spin diffusion to both pectins and cellulose ${ }^{30}$, also consistent with the model that a sizeable fraction of the cellulose microfibril surface is coated by pectins.

These SSNMR data suggest a cell-wall model that highlights limited but mechanically important XyG-cellulose interactions and extensive pectin-cellulose spatial contacts ${ }^{26,31}$. The significant pectin-cellulose interactions were unexpected for two reasons. First, they appear at odds with in vitro binding assays that show that pectins have much lower binding capacity than XyG for cellulose ${ }^{32-35}$. For example, arabinan-rich beet pectins exhibit a binding capacity of $\sim 10$ $\mu \mathrm{g}$ per mg cellulose, while the XyG binds cellulose at $\sim 120 \mu \mathrm{g}$ per mg cellulose ${ }^{36}$. Only XyGcellulose junctions bind expansins and respond to endoglucanase digestions, whereas pectin digestion does not induce significant creep extension in isolated wall samples ${ }^{21}$. But the apparent discrepancies between binding assays and SSNMR-detected pectin-cellulose cross peaks may be reconciled if pectins were entrapped within each microfibril or between microfibrils during synthesis, transport, and assembly of the cell wall, a process that is difficult to replicate in vitro. Indeed, recent studies of cellulose synthesis and hydrogel formation in the presence of pectin solutions found that $20-40 \%$ of pectins interact intimately with cellulose during assembly, as manifested by increased microfibril diameters in small-angle X-ray scattering data, denser networks of cellulose microfibrils in scanning electron micrographs, and altered viscoelastic and deformation properties of cellulose-pectin hydrogels compared to pure 
cellulose gels ${ }^{37,38}$.

A second reason for the skepticism about extensive pectin-cellulose interactions in cell walls is that it has not yet been shown whether these interactions are important for wall mechanics ${ }^{21,23}$, i.e. if perturbing the pectin-cellulose interactions can result in cell walls with altered mechanical and growth properties. Mutagenesis has been a valuable tool for understanding the structure-function relationships of cellulose and $\mathrm{XyG}$ in plant cell walls. For example, mutations in CELLULOSE SYNTHASE genes, cesa $1^{\text {aegeus }}$ and cesa $3^{\text {ixrl-2 }}$, in Arabidopsis were shown by SSNMR and X-ray diffraction to disrupt cellulose organization, causing microfibrils with substantially lower crystallinity and an additional conformation of glucan chains ${ }^{39}$. xxt $1 x x t 2$ mutants that lack $\mathrm{XyG}{ }^{40}$ were found to exhibit much shorter ${ }^{13} \mathrm{C}$ and ${ }^{1} \mathrm{H}$ relaxation times for cellulose and pectins compared to wild-type controls, indicating that XyG depletion increases the mobility of the remaining wall polysaccharides ${ }^{22}$. Another cellulosedeficient mutant, cesa $7^{\text {irx } 3-7}$, was used to probe xylan-cellulose interactions in secondary cell walls. Whereas xylan flattens into a two-fold helical screw conformation to bind to the surface of cellulose in wild-type secondary cell walls, xylan in the cesa $7^{\text {irx 3-7 }}$ mutant lacks this two-fold conformation ${ }^{41,42}$. Similar to these cellulose and XyG mutants, plants with altered pectin biosynthesis and processing should also be useful for elucidating how pectin-cellulose interactions impact wall structure and loosening ${ }^{8,43}$. Putative pectin biosynthetic mutants that are defective in extractable pectin content and esterification are known ${ }^{44-48}$, but several of these mutants also have altered xylan content. Recently, mutants overexpressing or lacking polygalacturonase genes have been shown to have altered HG molecular weights ${ }^{43,49}$, thus opening up the possibility of characterizing cell walls with different pectin molecular weight profiles but potentially normal pectin biosynthesis.

In this study, we use SSNMR spectroscopy to examine the structures and mobilities of 
polysaccharide in two Arabidopsis mutant cell walls with altered pectin molecular weights. The $P G X 1$ gene encodes a polygalacturonase that hydrolyzes the HG backbone. A $P G X 1^{A T}$ activation tagged mutant overexpresses $P G X 1$ and has higher total polygalacturonase activity, resulting in an average $\mathrm{HG}$ molecular weight of $\sim 66 \mathrm{kDa}^{43}$, which is lower than the wild-type HG molecular weight of $\sim 150 \mathrm{kDa}$. This $P G X 1^{A T}$ mutant shows taller etiolated seedlings and larger adult plants than wild-type Arabidopsis. In comparison, a pgx1-2 knockout mutant ablates $P G X 1$ expression, resulting in a higher $\mathrm{HG}$ molecular weight of $\sim 200 \mathrm{kDa}$. The knockout mutant produces shorter etiolated seedlings and smaller adult plants ${ }^{43}$. Using ${ }^{13} \mathrm{C}$ solid-state NMR, we show that the cell walls of these two mutants have altered pectin dynamics and pectin-cellulose interactions from each other and from the control cell wall. For the low-MW $P G X 1^{A T}$ mutant, the dynamic pectin domain exhibits reduced $\mathrm{HG}$ and RG-I backbone mobilities but increased RG-I sidechain mobilities, whereas the rigid pectin domain exhibits increased backbone mobility and weaker pectin-cellulose cross peaks in the low-MW mutant cell wall. These results suggest that pectins regulate the growth properties of plant cell walls by interacting with cellulose and/or by establishing an interfibrillar matrix network, thus supporting the importance of pectin structure and pectin-cellulose interactions for controlling wall dynamics during cellular growth.

\section{Material and Methods}

\section{Uniform ${ }^{13}$ C labeling and growth of wild-type and mutant cell walls}

${ }^{13}$ C-enriched Arabidopsis thaliana Columbia ecotype (Col-0), PGX1-overexpressed lowMW mutant $\left(P G X 1^{A T}\right)$ and $P G X 1$-depleted high-MW mutant (pgx1-2) primary cell walls were prepared as previously described ${ }^{30,43}$. The seedlings were grown in $2.2 \mathrm{~g} / \mathrm{L}$ Murashige and Skoog (MS) liquid culture containing $0.5 \%{ }^{13} \mathrm{C}$-labeled glucose as the sole carbon source in the dark with shaking for 14 days before they were harvested. The ${ }^{13} \mathrm{C}$ labeling level is estimated to 
be close to $100 \%$ based on cross peak intensities in $2 \mathrm{D}{ }^{13} \mathrm{C}-{ }^{13} \mathrm{C}$ correlation spectra. The seedlings were ground into fine powder in liquid nitrogen, and samples were washed with $1.5 \%(\mathrm{w} / \mathrm{v})$ SDS for $3 \mathrm{~h}$ to solubilize cell membranes and proteins and inactivate endogenous wall-degrading enzymes. The material was thoroughly washed with water, incubated with $\alpha$-amylase $(5,000$ units per $30 \mathrm{~mL}$ ) from porcine pancreas (Sigma-Aldrich) in sodium MES buffer (pH 6.8) to remove starch, and then digested with Pronase (200 units, $5 \mathrm{mg}$ per $20 \mathrm{~mL}$, Sigma-Aldrich) in sodium MES buffer ( $\mathrm{pH} 7.5$ ) to digest proteins at $40^{\circ} \mathrm{C}$ overnight. Incubation in $1.5 \%(\mathrm{w} / \mathrm{v})$ SDS with shaking at room temperature for $1 \mathrm{~h}$ inactivated the Pronase. A total of $0.02 \%(\mathrm{w} / \mathrm{v}) \mathrm{NaN}_{3}$ was used in all solutions to inhibit microbial growth. The samples were centrifuged to remove bulk water ${ }^{30}$.

\section{Solid-state NMR spectroscopy}

All SSNMR spectra were measured on an $800 \mathrm{MHz}(18.8$ Tesla) and a $600 \mathrm{MHz}(14.1$ Tesla) Bruker Advance II HD spectrometer using $3.2 \mathrm{~mm}$ magic-angle-spinning (MAS) ${ }^{1} \mathrm{H} /{ }^{13} \mathrm{C} /{ }^{15} \mathrm{~N}$ probes. Typical radiofrequency field strengths were $40-62.5 \mathrm{kHz}$ for ${ }^{13} \mathrm{C}$ and $50-80$ $\mathrm{kHz}$ for ${ }^{1} \mathrm{H} .{ }^{1} \mathrm{H}$ two-pulse phase modulation (TPPM) decoupling was applied during acquisition. All ${ }^{13} \mathrm{C}$ chemical shifts were externally referenced to the adamantine $\mathrm{CH}_{2}$ peak at 38.48 ppm on the tetramethylsilane (TMS) scale.

$1 \mathrm{D}{ }^{13} \mathrm{C}$ MAS spectra were measured at $296 \mathrm{~K}$ under $10 \mathrm{kHz}$ MAS on the $800 \mathrm{MHz}$ spectrometer using ${ }^{1} \mathrm{H}_{-}{ }^{13} \mathrm{C}$ cross polarization $(\mathrm{CP})$ or ${ }^{13} \mathrm{C}$ direct polarization (DP) to generate the initial magnetization. Quantitative ${ }^{13} \mathrm{C}$ spectra were measured using ${ }^{13} \mathrm{C}$ DP and a recycle delay of 30 s. ${ }^{13} \mathrm{C}$ CP spectra were measured using a contact time of $1 \mathrm{~ms}$ and a recycle delay of $2 \mathrm{~s}$. Refocused INEPT ${ }^{50}$ spectra were measured using a total polarization transfer time of $6 \mathrm{~ms}$, which consists of two delays of $1.8 \mathrm{~ms}$ followed by two delays of $1.2 \mathrm{~ms}$. These values 
correspond to $1 /\left(4 \mathrm{~J}_{\mathrm{CH}}\right)$ and $1 /\left(6 \mathrm{~J}_{\mathrm{CH}}\right)$, respectively, assuming a standard ${ }^{1} \mathrm{~J}_{\mathrm{CH}}$ value of $140 \mathrm{~Hz}{ }^{51}$. A recycle delay of $3.5 \mathrm{~s}$ was used for the INEPT experiments.

$2 \mathrm{D}{ }^{13} \mathrm{C}-{ }^{13} \mathrm{C}$ J-INADEQUATE spectra ${ }^{52,53}$ correlating the double-quantum and singlequantum ${ }^{13} \mathrm{C}$ chemical shifts were measured to assign the resonances of matrix polysaccharides. The experiments were carried out on the $800 \mathrm{MHz}$ spectrometer at $296 \mathrm{~K}$ under $12 \mathrm{kHz}$ MAS. To preferentially detect dynamic components of the cell wall, the initial ${ }^{13} \mathrm{C}$ magnetization was generated using a ${ }^{13} \mathrm{C} 90^{\circ}$ pulse and the recycle delay was $2 \mathrm{~s}$. The spectral widths were $333 \mathrm{ppm}$ $(67 \mathrm{kHz})$ and $83 \mathrm{ppm}(17 \mathrm{kHz})$ for the direct and indirect dimensions, respectively. A total of $320 t_{1}$ increments were collected, and the number of scans per $t_{1}$ increment was 128 for the lowMW mutant and wild-type cell walls and 256 for the high-MW mutant.

2D ${ }^{1} \mathrm{H}$-driven ${ }^{13} \mathrm{C}$ spin diffusion (PDSD) spectra were measured on the $600 \mathrm{MHz}$ spectrometer under $10 \mathrm{kHz}$ MAS, using a CP contact time of $300 \mu \mathrm{s}$, a spin diffusion mixing time of $1.5 \mathrm{~s}$, and a recycle delay of $1.3 \mathrm{~s}$. The spectra were measured at $253 \mathrm{~K}$ to immobilize the pectins. The spectral widths were $331 \mathrm{ppm}(50 \mathrm{kHz})$ and $110 \mathrm{ppm}(17 \mathrm{kHz})$ for the direct and indirect dimensions, the $\mathrm{t}_{1}$ increments were 122 and 132 for the low-MW mutant and high-MW mutant, respectively, and the corresponding numbers of scans were 192 and 352.

Dipolar-doubled ${ }^{13} \mathrm{C}-{ }^{1} \mathrm{H}$ dipolar chemical-shift correlation (DIPSHIFT) experiments were carried out on the $800 \mathrm{MHz}$ spectrometer at $296 \mathrm{~K}$ under $9.2 \mathrm{kHz}$ MAS ${ }^{54,55}$, using a recycle delay of 2.7 s. ${ }^{1} \mathrm{H}$ homonuclear decoupling was achieved using the FSLG ${ }^{56}$ pulse sequence with a ${ }^{1} \mathrm{H}$ transverse field strength of $80 \mathrm{kHz}$. The FSLG scaling factor of 0.577 was verified using the model peptide formyl-Met-Leu-Phe-OH ${ }^{57,58}$. A $3: 1$ combination of dipolar couplings $\delta$ and $3 \delta$ was used to simulate the DIPSHIGT curves of $\mathrm{CH}_{3}$ groups ${ }^{55}$. The ratios between the experimentally measured couplings and the effective rigid-limit $\mathrm{C}-\mathrm{H}$ dipolar coupling of 26.2 $\mathrm{kHz}$ gave the order parameters, $\mathrm{S}_{\mathrm{CH}}, \mathrm{S}_{\mathrm{CH} 2}$ and $\mathrm{S}_{\mathrm{CH} 3}$. 


\section{Results}

\section{Polysaccharide compositions of mutant cell walls from quantitative ${ }^{13}$ C spectra}

We first compare the polysaccharide compositions of wild-type and mutant cell walls using quantitative ${ }^{13} \mathrm{C}$ spectra (Fig. 1A). These spectra were measured using a recycle delay of $30 \mathrm{~s}$, which is more than 5-times longer than the ${ }^{13} \mathrm{C} \mathrm{T}_{1}$ relaxation times of $0.3-5 \mathrm{~s}$ for these uniformly ${ }^{13} \mathrm{C}$-labeled Arabidopsis cell walls ${ }^{27,28}$. These ${ }^{13} \mathrm{C} \mathrm{T}_{1}$ relaxation times are significantly shorter than the $\mathrm{T}_{1}$ 's of unlabeled cell walls ${ }^{59}$ because ${ }^{13} \mathrm{C}$ spin diffusion efficiently transfers magnetization from relaxation hotspots to all nearby ${ }^{13} \mathrm{C}$ sites. The different cell walls show similar linewidths in the quantitative ${ }^{13} \mathrm{C}$ spectra, thus allowing us to use peak heights to report polysaccharide concentration differences among the three cell walls. To account for sample amount differences, we normalized the peak intensities by the integrated spectral intensities, excluding the 25-30 ppm lipid region. Relative to the high-MW spectrum, the low-MW mutant and wild-type spectra were scaled by a factor of 0.64 and 0.95 , respectively.

Careful inspection of the HG and RG-I peak intensities in the quantitative spectra gave detailed information about changes in methyl esterification and sidechain decoration of the pectins among the three cell walls. First, the two mutants show much higher intensities of the 108-ppm arabinose (Ara) C1 signal than the wild-type cell wall, indicating that the mutants have higher concentrations of Ara sidechains. Second, the wild-type and high-MW cell walls have the same intensities for the 100-ppm GalA and Rha C1 peak, the 174-ppm acetyl carbonyl peak, and the 176-ppm $\mathrm{COO}^{-}$peak, whereas the low-MW cell wall exhibits different intensities. Specifically, the low-MW mutant has the same or higher intensities for the 101-ppm GalA and Rha C1 peak, the 174-ppm acetyl peak, and the 172-ppm methyl ester carbonyl peak, but lower intensities for the 100-ppm peak and the 176-ppm $\mathrm{COO}^{-}$peak. We can distinguish the 
assignment of the 100-ppm and 101-ppm peaks based on their correlated intensity changes with the carbonyl peaks. Since the 176-ppm peak results from unesterified carboxyl groups, its intensity reduction along with the 100-ppm peak suggests that the 100 -ppm peak can be assigned to $\mathrm{C} 1$ of unesterified and negatively charged GalA. Moreover, although GalA is present in both HG and RG-I, the 100-ppm peak can be specifically assigned to HG for the following reason. The Rha concentration has been previously found to be similar between wild-type and mutant cell walls of 6-day-old dark-grown seedlings ${ }^{43}$. Consistently, our current 14-days-old seedling samples show similar Rha C6 peak intensities for all three cell walls, indicating that the RG-I concentration is similar among the three cell walls. Therefore, the lower intensity of the 100-ppm peak in the low-MW cell wall can be attributed mainly to a lower concentration of the negatively charged HG compared to the high-MW and wild-type cell walls. Further supporting this conclusion, the 54-ppm methyl ester peak is higher in the low-MW spectrum than the other two spectra, indicating a higher HG esterification level. Finally, the low-MW mutant shows higher 21-ppm $\mathrm{OCO}^{-} \mathrm{H}_{3}$ and 174-ppm $\mathrm{OCOCH}_{3}$ peak intensities than the other two cell walls, indicating a higher acetylation level. Taken together, these observations indicate that the lowMW mutant has increased HG methyl esterification and acetylation and correspondingly lower amounts of negatively charged $\mathrm{COO}^{-}$groups.

\section{Dynamics of matrix polysaccharides from INEPT ${ }^{13}$ C spectra}

To selectively detect highly mobile polysaccharides, we measured ${ }^{13} \mathrm{C}$ INEPT (Insensitive Nuclei Enhanced by Polarization Transfer) spectra (Fig. 1B). During J-coupling based ${ }^{1} \mathrm{H}-{ }^{13} \mathrm{C}$ polarization transfer, no ${ }^{1} \mathrm{H}-{ }^{1} \mathrm{H}$ homonuclear decoupling was applied, thus the signals of rigid polysaccharides were suppressed by ${ }^{1} \mathrm{H}-{ }^{1} \mathrm{H}$ dipolar couplings ${ }^{50}$. The INEPT spectra show much higher resolution than the quantitative spectra: ${ }^{13} \mathrm{C}-{ }^{13} \mathrm{C} \mathrm{J}$ splittings can be resolved for some of the matrix polysaccharide signals, and the cellulose signals at $105 \mathrm{ppm}, 89$ 
ppm, 70-78 ppm, and 60-66 ppm are largely suppressed. The removal of the interior cellulose C4 peak revealed an 88-ppm Ara C2 peak. 2D ${ }^{13} \mathrm{C}$ INADEQUATE spectra (see below) indicate that this 88-ppm peak can be assigned to Ara types a, f and g (Table 1). Indeed, multiple Ara C2 and C4 peaks between 80 and 90 ppm are resolved and can be assigned to various subtypes based on the 2D J-INADEQUATE spectra. In addition, several GalA C1 peaks are resolved at $101 \mathrm{ppm}$ (type b), 100 ppm (types a and e), 99 ppm (type g), and 98 ppm (type i). Based on the intensity ratios between the INEPT spectra and the quantitative spectra, and the expected 4-fold sensitivity enhancement by the INEPT polarization transfer, we estimate that these highly mobile polysaccharides account for less than $10 \%$ of the total matrix polysaccharide population.

More precise information about the polysaccharide composition and dynamics of the two mutant cell walls can be obtained by analyzing the peak height ratios between the low- and highMW cell walls, taking into account sample amount differences. Since the two mutant cell walls have similar linewidths, the ratios of the quantitative spectral intensities report the relative polysaccharide concentrations whereas the ratios of the INEPT spectral intensities report the relative mobilities of the polysaccharides. Fig. 2 shows that the two mutants have near-unity intensity ratios for most peaks in the quantitative spectra, except for the 108-ppm Ara C1 peak, the 100-ppm GalA C1 peak, and the 54-ppm methyl-ester peak, whose intensity ratios are 1.2, 0.7 and 1.2. Since the 54-ppm and 100-ppm peaks have varying contributions from neighboring ${ }^{13} \mathrm{C}$ signals, we used spectral deconvolution to obtain more precise intensity values for these two peaks (Fig. S1). After deconvolution, the relative intensities for the 54-ppm peak are 1.18, 1.00 and 1.14 for the low-MW mutant, high-MW mutant and wild-type cell wall, respectively, while the relative intensities of the $100-\mathrm{ppm}$ peak are $0.81,1.00$ and 1.05 for the three cell walls, in good agreement with the results without deconvolution. 
Compared to the quantitative spectra, the INEPT intensity ratios between the low- and high-MW mutants deviate more substantially from 1, indicating different dynamics of the mobile polysaccharides that are selectively detected in the INEPT spectra. In particular, the Ara and Gal signals at 110 ppm and 108 ppm have INEPT intensity ratios of 1.5 and 1.4, respectively (Fig. 2), which are much larger than the corresponding quantitative intensity ratios, indicating that the low-MW mutant has much more mobile Ara sidechains than the high-MW mutant. Compared to pectins, xyloglucan exhibits the opposite intensity trend: the 99.5-ppm Xyl C1 signal has an INEPT intensity ratio of less than 1.0, indicating that the low-MW $P G X 1^{A T}$ mutant has more rigid XyG compared to the high-MW cell wall.

The HG and RG-I backbones show an opposite mobility trend from the pectin sidechains in the INEPT-detected spectra. The GalA and Rha signals such as the 69-ppm GalA C2 signal, the 18-ppm Rha C6 signal, and the 98.5-ppm GalA C1 signal, exhibit lower INEPT intensity ratios than the quantitative intensity ratios, indicating that the low-MW cell wall has more rigid HG and RG-I backbones than the high-MW cell wall. Most prominently, the 100-ppm HG GalA $\mathrm{C} 1$ peak (type a and e) has the lowest INEPT intensity ratio of 0.4 among all ${ }^{13} \mathrm{C}$ signals (Fig. 1B, Fig. 2), indicating that the negatively charged $\mathrm{HG}$ is much more immobilized in the low-MW cell wall than in the high-MW mutant. The INEPT intensities of the 100-ppm, 54-ppm and 18ppm peaks indicate that the HG and RG-I backbones are the most rigid in the low-MW mutant, intermediate in the wild-type cell wall, and the most dynamic in the high-MW mutant (Fig. S2). Since the INEPT experiment detects only the most mobile population of matrix polysaccharides, these changes pertain to $\mathrm{HG}$ in the interfibrillar domain. The data suggest that the shorter $\mathrm{HG}$ chains in the low-MW cell wall are aggregated and/or constrained by other polysaccharides compared to the longer HG chains in the high-MW cell wall. 
We also compared the two mutants with the wild-type cell walls using peak height ratios $H_{\text {Low MW }} / H_{\text {Wild type }}$ and $H_{\text {High Mw }} / H_{\text {Wild type }}$ (Fig. S2). Again, we focus on the polysaccharide signals, while the ${ }^{13} \mathrm{C}$ signals of lipids between 25 and $35 \mathrm{ppm}$, which do not originate from the cell walls, are not considered. Between the high-MW mutant and wild-type cell walls, and between the low-MW and wild-type cell walls, the intensity ratios of the quantitative spectra are close to 1 except for the 100-ppm non-methylated HG signal. In contrast, the pectin sidechain INEPT intensity ratios between the low-MW and wild-type cell walls are larger than those between the high-MW and wild-type cell walls. These results indicate that the three cell walls have similar polysaccharide compositions except for the negatively charged HG concentration, and the sidechains are similarly mobile between high-MW and wild-type cell walls but much more mobile in the low-MW cell wall.

\section{Compositions of $H G$ and $X y G$ from $2 D{ }^{13}$ C INADEQUATE spectra}

To fully resolve the matrix polysaccharide signals, we measured $2 \mathrm{D}{ }^{13} \mathrm{C}-{ }^{13} \mathrm{C} \mathrm{J}$ INADEQUATE spectra (Fig. 3), which use ${ }^{13} \mathrm{C}-{ }^{13} \mathrm{C}$ J-coupling to transfer ${ }^{13} \mathrm{C}$ coherence and correlate the sum of the chemical shifts of two directly bonded ${ }^{13} \mathrm{C}$ spins with the chemical shift of each ${ }^{13} \mathrm{C}^{22,52}$. In addition to scalar-coupling based polarization transfer, the 2D spectra were measured using direct ${ }^{13} \mathrm{C}$ polarization and a short recycle delay of $2 \mathrm{~s}$ to preferentially detect the signals of mobile polysaccharides. About $90 \%$ of the matrix polysaccharides were observed in the 2D INADEQUATE spectra, as estimated based on the fact that $1 \mathrm{D}^{13} \mathrm{C}$ DP spectra measured with a 2 s recycle delay showed $\sim 90 \%$ of the matrix polysaccharide signals compared to the quantitative spectra.

Fig. 3 shows the 2D INADEQUATE spectrum of the low-MW cell wall. Similar to previously studied cell walls, the spectrum is dominated by pectin signals with narrow linewidths 
of 0.4-0.8 ppm, followed by a small number of xylose peaks. Multiple linkages were detected for the matrix polysaccharides, including eight types of Ara, six types of Gal, five types of GalA, four types of Rha and two types of Xyl (Table 1). Comparison of specific spectral regions between the low-MW and high-MW samples (Fig. 4) indicates that the two mutants differ mainly in peak intensities rather than chemical shifts. For example, type-a, i GalA intensities are lower by $10-70 \%$, and type-a and type-b Xyl intensities are lower by $\sim 10 \%$ and $\sim 70 \%$ in the lowMW cell wall (Fig. 4C). Since the Rha content is the same between the two mutants ${ }^{43}$, these GalA intensity changes can be attributed to $\mathrm{HG}$, indicating that the low-MW $P G X 1^{A T}$ cell wall contains less dynamic HG and XyG than the pgx 1-2 cell wall, consistent with the INEPT data. The GalA signals in the INADEQUATE spectra are similar between wild-type and high-MW cell walls, (Fig. 5), also consistent with the quantitative spectra (Fig. 1A). Finally, both mutants show higher Ara and Gal intensities than the wild-type cell wall, consistent with the quantitative ${ }^{13} \mathrm{C}$ spectra (Fig. 1A), indicating that the mutants have more RG-I sidechains than the wild-type cell wall.

\section{C-H dipolar order parameters}

To investigate whether $P G X 1$ mutation affects the dynamics of more rigid polysaccharides that are not well detected by the INEPT and INADEQUATE experiments, we measured ${ }^{13} \mathrm{C}-{ }^{1} \mathrm{H}$ dipolar couplings using the dipolar chemical-shift (DIPSHIFT) correlation experiment (Fig. 6) ${ }^{54,55} \cdot{ }^{1} \mathrm{H}_{-}{ }^{13} \mathrm{C}$ cross polarization (CP) was used to create the initial ${ }^{13} \mathrm{C}$ magnetization, thus the experiment selectively detects the rigid wall polysaccharides, including cellulose and $\sim 40 \%$ of the matrix polysaccharides, as estimated from comparisons of the CP spectra and quantitative spectra. Fig. 6B shows the $\mathrm{C}-\mathrm{H}$ dipolar dephasing curves and the corresponding order parameters of all major polysaccharides. As expected, cellulose exhibits near rigid-limit order parameters for all three cell walls. For matrix polysaccharides, the low- 
MW $P G X 1^{A T}$ cell wall shows moderately larger order parameters than wild-type cell walls, while the high-MW pgx1-2 mutant has much larger order parameters than both control and low-MW cell walls (Fig. 6C). The largest difference between the two mutants is found for the 101-ppm peak, the 84.7-ppm peak, the 62.6-ppm peak, and the 54-ppm methyl ester peak. Since the CPDIPSHIFT spectrum preferentially detects more rigid pectins, these results indicate that pectincellulose interaction is weaker in the control and low-MW $P G X 1^{A T}$ cell walls than in the highMW mutant. In particular, the high-MW mutant exhibits a large order parameter of 0.42 for the 54-ppm methyl ester peak, suggesting that the three-site jump motions of $\mathrm{CH}_{3}$ groups are significantly impeded by polysaccharide interactions.

\section{Cellulose-pectin proximities from $2 D^{13} C-{ }^{13}$ C correlation spectra}

To further investigate whether cellulose-pectin interactions differ between the two mutants, we measured 2D ${ }^{13} \mathrm{C}$ PDSD spectra using a long ${ }^{13} \mathrm{C}$ mixing time of $1.5 \mathrm{~s}$ (Fig. 7). The spectra exhibit extensive cellulose-pectin cross peaks such as the interior cellulose C4 and C6 correlations to the $\mathrm{C} 1$ peak of $\mathrm{Xyl}, \mathrm{GalA}$, or Rha at (89 ppm, $101 \mathrm{ppm})$ and (65 ppm, $101 \mathrm{ppm})$. Importantly, in the 89-ppm and 65-ppm cross sections of interior cellulose, the low-MW cell wall shows weaker pectin cross peaks than the high-MW mutant. Examples include the 108-ppm peak of Ara C1, the 80-ppm peak of Ara/Rha C2 and Gal/GA C4, and the 69.7-ppm peak of a mixture of pectin and Xyl carbons (Fig. 7C). Conversely, in the 101-ppm and 69-ppm cross sections of pectin carbons, the low-MW cell wall exhibits weaker cellulose cross peaks at 89 ppm and 65 ppm than the high-MW mutant. These results indicate that the low-MW $P G X 1^{A T}$ cell wall has weaker interactions between cellulose and the rigid domain of HG and RG-I, which is consistent with the higher HG and RG-I backbone mobilities of the $P G X 1^{A T}$ cell wall seen in the CP-DIPSHIFT data. 


\section{Discussion}

These SSNMR data, together with previous biochemical characterization of $P G X 1$ mutants ${ }^{43}$, shed light on how cellulose-pectin interactions and pectin conformational dynamics correlate with the extensibility of primary cell walls ${ }^{28,60} . P G X 1$ mutations alter HG molecular weight and either promote $\left(P G X 1^{A T}\right)$ or limit (pgx 1-2) cell expansion, hypocotyl elongation, and adult plant growth ${ }^{43}$. These changes in cell and organ growth may be attributed to changes in the characteristics and behaviors of $\mathrm{HG}$ : in $P G X 1^{A T}$ cell walls, the increased polygalacturonase activity is expected to degrade regions of $\mathrm{HG}$ chains with low esterification, which should shorten HG chains, attenuate the calcium-crosslinked pectin network, and in turn cause a looser wall. The reverse should be true for the pgxl-2 mutant, where a reduction in total polygalacturonase activity is expected to give rise to longer HG chains with low esterification, which may then crosslink via calcium, stiffen the wall and diminish wall expansibility and cell growth. Pectinase treatment can restore expansin activity in cucumber hypocotyls ${ }^{61}$, implying that pectins also limit wall expansibility in that species.

The solid-state NMR data shown here support some aspects of the above hypothesis but also reveal unexpected structural and dynamical features of the pectin network. Fig. 8 summarizes the findings from the SSNMR data and compares the polysaccharide mobilities and intermolecular interactions between the two mutant cell walls. The concentrations of most polysaccharides are similar between the two mutant walls, with the exception that the low-MW $P G X 1^{A T}$ cell wall has significantly lower amounts of negatively charged carboxyl groups and higher esterification of $\mathrm{HG}$. The enrichment of methyl-esterified HG in $P G X 1^{A T}$ walls may result from the resistance of esterified $\mathrm{HG}$ to degradation by PGX1 and other polygalacturonases. Alternatively, it could arise from higher levels of synthesis and/or exocytosis of new highly esterified HG due to pectin degradation and oligogalacturonide release, although the similar 
levels of total pectic HG content between $P G X 1^{A T}$ and wild-type walls (Fig. 1A) argue against this idea. A third possibility is that the increased polygalacturonase activity and the resulting higher levels of oligogalacturonides ${ }^{62}$ may up-regulate HG esterification during HG synthesis or down-regulate HG de-esterification by pectin methyl-esterases.

The different HG esterification is coupled with complex mobility changes between the low- and high-MW mutant cell walls. The mobilities change in opposite directions for the dynamic and rigid domains. For the dynamic pectin domain between cellulose microfibrils, the low-MW cell wall has more immobilized HG and RG-I backbones but more dynamic arabinan and galactan sidechains compared to the high-MW cell wall. We attribute the backbone immobilization to partial HG aggregation in the interfibrillar space. This could occur via one of two mechanisms. First, the increased HG esterification in the low-MW mutant would be expected to reduce calcium crosslinking, thus hindering the formation of an open, well-spaced pectin network in the interfibrillar space (Fig. 8B). Alternatively, the lower negative charge of HG might increase intermolecular interactions between HG chains or between HG and RG-I or RG-II ${ }^{10,12}$, thus facilitating aggregation. HG aggregation can in turn create open regions in which RG-I sidechains can undergo larger-amplitude motions. In contrast to the mobile pectin domain, the CP-DIPSHIFT spectra show that the rigid pectin domain that interacts with cellulose becomes less rigid in the low-MW cell wall and shows weaker cross peaks with cellulose in 2D ${ }^{13} \mathrm{C}-{ }^{13} \mathrm{C}$ correlation spectra. This could result from less crosslinking of $\mathrm{HG}$ in the vicinity of cellulose or shorter HG chains that have limited interactions with cellulose. Taken together, these data suggest that the enhanced cellular growth observed in the low-MW $P G X 1^{A T}$ mutant may result from a less crosslinked pectin network and weaker pectin-cellulose interactions, both of which can facilitate wall loosening and expansion. 
These SSNMR data imply that it is the pectin backbones rather than sidechains that interact with cellulose to regulate wall extensibility, even though in vitro binding assays found that the neutral arabinan and galactan sidechains are better than the charged pectin backbones in binding cellulose 16, 36, 63. That RG-I sidechains do not play a significant role in cellulose interactions in planta is supported by the fact that Ara and Gal show strong signals in the INEPT spectra while negligible intensities in the CP spectra. The lack of extensive interactions between pectin sidechains and cellulose might be due to conformational disorder of the sidechains, while the stronger interactions of $\mathrm{HG}$ backbone with cellulose might be mediated by favorable $\mathrm{HG}$ backbone conformations. $P G X 1$ overexpression, by reducing the molecular weight and increasing the esterification of $\mathrm{HG}$, simultaneously weakens $\mathrm{HG}$-cellulose interactions and causes partial aggregation of the interfibrillar HG. It remains to be determined how HG synthesis, esterification and de-esterification in the wall might be altered in $P G X 1$ mutants to compensate for changes in HG auto-degradation. We hypothesize that this could occur via wall-integritysensing pathways that detect HG degradation products such as oligogalacturonides ${ }^{64}$. Pectin degradation might indirectly affect wall composition and architecture by activating defense responses and/or wall integrity-sensing pathways ${ }^{62}$. This is an especially attractive idea if PGX1 acts as an endo-polygalacturonase, which seems likely from the $\sim 2.3$-fold changes in $\mathrm{HG}$ molecular weight observed in the $P G X 1^{A T}$ cell walls ${ }^{43}$, and produces high levels of oligogalacturonides. When expressed heterologously, PGX1 possesses at least 10-fold higher polygalacturonase activity than three other Arabidopsis polygalacturonases 43 , 65, and total polygalacturonase activity increased by $\sim 50 \%$ in $P G X 1^{A T}$ leaves and decreased by $\sim 50 \%$ in $p g x 1$ 2 leaves relative to wild-type ${ }^{43}$. It is thus somewhat surprising that only 2-3 additional cuts per HG molecule appear to occur. Experiments to detect oligogalacturonide levels and wall-integrity activation in $P G X 1$ mutants should be informative to answer these questions. 
The fact that a decrease and increase of HG molecular weight in the $P G X 1^{A T}$ and $p g x 1-2$ cell walls causes enhanced and diminished hypocotyl elongation, respectively, suggests that in the wild-type cell wall, homogalacturonan-cellulose interactions and pectin network formation play an important role in constraining cell growth. We speculate that this constraining effect may be directional to control the anisotropy of cell expansion ${ }^{66}$. Finally, the INEPT spectra show that $\mathrm{XyGs}$ become more rigid in the low-MW mutant, suggesting that $\mathrm{XyG}$ may compensate for weaker pectin-cellulose interactions by binding more extensively to cellulose, as a larger microfibril surface area becomes available. Future biomechanical, genetic, and structural analyses should help to delineate how cellulose-pectin and cellulose-XyG interactions might work in a concerted fashion to regulate wall dynamics during plant growth.

\section{Conclusion}

The current solid-state NMR data on the pectin mutant cell walls reveal the importance of homogalacturonan-cellulose interactions and pectin network formation in regulating cell wall growth. The low-MW mutant, with increased PGX1 activity, lower HG molecular weight and longer hypocotyls, exhibits distinct polysaccharide compositions, dynamics and intermolecular proximity to cellulose from control cell walls. The low-MW mutant has lower galacturonic acid, xylose and carboxylate contents and higher methyl esterification levels. The increased esterification leads to aggregation of $\mathrm{HG}$ and RG-I backbones in the interfibrillar space, likely because lower negative charges or reduced steric constraints hinder the formation of a wellspaced pectin network. The increased pectin backbone aggregation is correlated with increased mobility of the RG sidechains, likely due to increased space for sidechain motion. Further, the low-MW cell wall shows increased mobility of pectins that interact with cellulose. These results show that growth enhancement of the low-MW mutant is correlated with increased esterification, 
reduced crosslinking, and increased aggregation of interfibrillar pectins and weaker HG-cellulose microfibril interactions.

\section{Supporting Information}

Spectral deconvolution of selected signals in Fig. S1. Comparison of ${ }^{13} \mathrm{C}$ spectral intensities between the mutants and wild-type cell walls in Fig. $\mathbf{S 2}$.

\section{Corresponding Authors \\ *E-mail: meihong@mit.edu \\ *E-mail: cta3@psu.edu}

\section{Acknowledgements}

This research was supported by the Center for Lignocellulose Structure and Formation, an Energy Frontier Research Center funded by the U.S. Department of Energy, Office of Science, Basic Energy Sciences under Award \# DE-SC0001090. The authors thank Ed Wagner for assistance with ${ }^{13} \mathrm{C}$-labeling protocols and Daniel Cosgrove for helpful comments on the manuscript. 
Table 1. ${ }^{13} \mathrm{C}$ chemical shifts of matrix polysaccharides in the low-MW mutant (L), high-MW mutant (H) and wild-type (WT) cell walls. These chemical shifts are compared to previously reported polysaccharide chemical shifts found in 2-week old Arabidopsis seedling cell walls (2W) and inflorescence cell walls (I). Italicized chemical shifts are not resolved. Superscripts refer to subtypes of monosaccharides observed in this study. Some subtypes have been previously observed in the two-week old and inflorescence cell walls but are absent in the high- and low MW mutants. Very weak peaks such as Xyl-b in the low-MW cell wall are not included.

\begin{tabular}{|c|c|c|c|c|c|c|c|c|}
\hline Sugar & Linkage & Cell walls & $\begin{array}{c}\mathrm{C} 1 \\
(\mathrm{ppm})\end{array}$ & $\begin{array}{c}\mathrm{C} 2 \\
(\mathrm{ppm})\end{array}$ & $\begin{array}{c}\mathrm{C} 3 \\
\text { (ppm) }\end{array}$ & $\begin{array}{c}\mathrm{C} 4 \\
(\mathrm{ppm})\end{array}$ & $\begin{array}{c}\mathrm{C} 5 \\
(\mathrm{ppm})\end{array}$ & $\begin{array}{c}\mathrm{C} 6 \\
(\mathrm{ppm})\end{array}$ \\
\hline $\operatorname{Ara}^{\mathrm{a}}$ & 2,5-Ara & $\mathrm{L}, \mathrm{H}, \mathrm{I}$ & 107.1 & 87.7 & - & - & - & \\
\hline $\mathrm{Ara}^{\mathrm{b}}$ & 2,5-Ara & $\mathrm{L}, \mathrm{H}, \mathrm{I}$ & 107.0 & 85.8 & - & - & - & \\
\hline $\operatorname{Ara}^{c}$ & 5-Ara & $\mathrm{L}, \mathrm{H}, \mathrm{I}, 2 \mathrm{~W}, \mathrm{WT}$ & 108.2 & 81.8 & 77.7 & 83.1 & 67.6 & \\
\hline $\mathrm{Ara}^{\mathrm{d}}$ & t-Ara & all & 107.7 & 82.3 & 77.4 & 84.5 & 62.0 & \\
\hline $\mathrm{Ara}^{\mathrm{e}}$ & - & $\mathrm{L}, \mathrm{H}, \mathrm{I}, 2 \mathrm{~W}$ & 108.2 & 80.1 & - & - & - & \\
\hline $\operatorname{Ara}^{\mathrm{f}}$ & 2,5-Ara & $\mathrm{L}, \mathrm{H}, 2 \mathrm{~W}, \mathrm{WT}$ & 108.5 & 88.0 & - & - & - & \\
\hline $\mathrm{Ara}^{\mathrm{g}}$ & 2,5-Ara & $\mathrm{L}, \mathrm{H}, \mathrm{WT}$ & 108.6 & 87.4 & - & - & - & \\
\hline $\mathrm{Ara}^{\mathrm{h}}$ & 5-Ara & all & 109.9 & 82.0 & - & - & - & \\
\hline $\mathrm{Xyl}^{\mathrm{a}}$ & $\begin{array}{c}\text { t-Xyl of } \\
\text { XvG }\end{array}$ & all & 99.6 & 72.2 & 74.3 & 70.2 & 62.3 & \\
\hline $\mathrm{Xyl}^{\mathrm{b}}$ & & $\mathrm{H}$ & 99.0 & 72.5 & - & 69.3 & 62.4 & \\
\hline $\mathrm{Gal}^{\mathrm{a}}$ & 4-Gal & all & 105.1 & 72.8 & 74.0 & 78.4 & 75.2 & 61.5 \\
\hline $\mathrm{Gal}^{\mathrm{b}}$ & t-Gal & all & 105.2 & 72.0 & 73.4 & 69.5 & 75.6 & 61.7 \\
\hline $\mathrm{Gal}^{\mathrm{c}}$ & - & $\mathrm{L}, \mathrm{H}, \mathrm{I}, 2 \mathrm{~W}$ & 104.1 & 72.6 & - & - & - & - \\
\hline $\mathrm{Gal}^{\mathrm{d}}$ & - & all & 103.4 & 73.8 & - & - & - & - \\
\hline $\mathrm{Gal}^{\mathrm{e}}$ & - & all & 104.1 & 71.4 & - & - & - & - \\
\hline $\mathrm{Gal}^{\mathrm{g}}$ & - & L,H,WT & 103.9 & 70.7 & - & - & - & - \\
\hline $\mathrm{GalA}^{\mathrm{a}}$ & 4-GalA & L,H,I,WT & 99.8 & 69.0 & 69.7 & 78.5 & $72.1 / 71.2$ & - \\
\hline $\mathrm{GalA}^{\mathrm{b}}$ & - & all & 101.0 & 68.6 & 71.3 & - & - & - \\
\hline $\mathrm{GalA}^{\mathrm{e}}$ & - & all & 100.1 & 69.5 & - & - & - & - \\
\hline $\mathrm{GalA}^{\mathrm{g}}$ & - & $\mathrm{L}, \mathrm{H}, 2 \mathrm{~W}, \mathrm{WT}$ & 98.8 & 67.8 & 72.4 & 77.8 & 71.2 & 171.5 \\
\hline $\mathrm{GalA}^{\mathrm{i}}$ & - & $\mathrm{L}, \mathrm{H}, 2 \mathrm{~W}, \mathrm{WT}$ & 98.2 & 68.7 & 69.7 & 78.5 & 72.1 & - \\
\hline Rha ${ }^{b}$ & - & all & - & - & - & - & 69.7 & 17.3 \\
\hline $\mathrm{Rha}^{\mathrm{c}}$ & - & all & - & - & - & - & 67.9 & 16.7 \\
\hline Rha $^{\mathrm{d}}$ & 2-Rha & $\mathrm{L}, \mathrm{H}, 2 \mathrm{~W}, \mathrm{WT}$ & - & 79.8 & 71.0 & 72.6 & 68.1 & 16.0 \\
\hline $\mathrm{Rha}^{\mathrm{e}}$ & & $\mathrm{L}, \mathrm{H}, \mathrm{WT}$ & - & - & - & - & 68.4 & 17.4 \\
\hline
\end{tabular}


A Quantitative DP
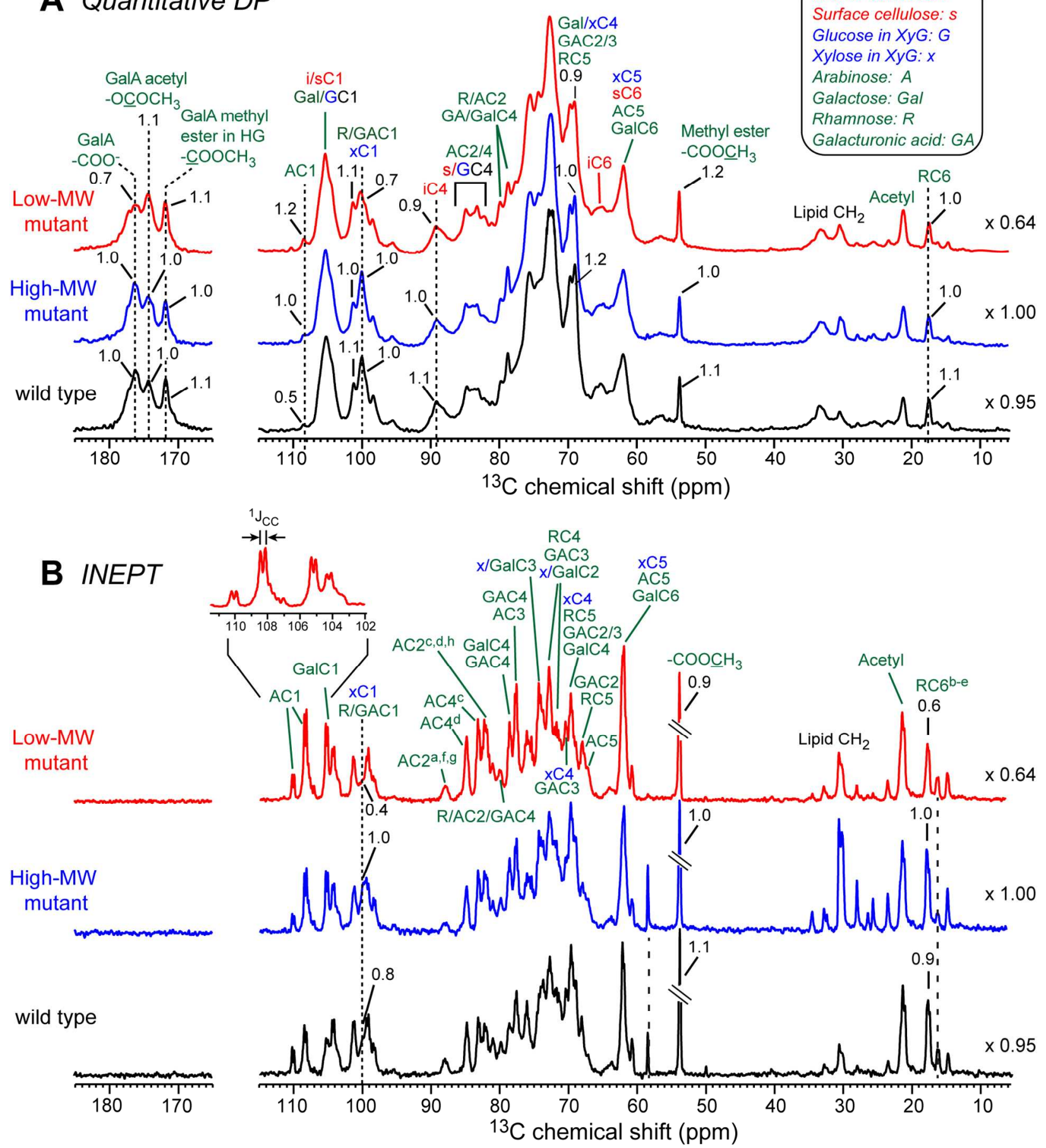

Figure 1. ${ }^{13} \mathrm{C}$ MAS spectra of the low-MW (red) mutant, high-MW mutant (blue) and wild-type (black) Arabidopsis cell walls. Polysaccharide abbreviations for ${ }^{13} \mathrm{C}$ resonance assignment are shown in the upper right corner. (A) Quantitative ${ }^{13} \mathrm{C}$ DP spectra, plotted after multiplying the low-MW spectral intensities by 0.64 fold and the wild-type spectral intensities by 0.95 fold to account for sample amount differences. Intensity values for selected peaks indicate relative 
intensities among the three cell walls, after taking into account sample amount differences. (B)

${ }^{13} \mathrm{C}$ INEPT spectra showing only the signals of highly mobile polysaccharides. ${ }^{13} \mathrm{C}-{ }^{13} \mathrm{C} \mathrm{J}$ couplings can be resolved for some peaks, as shown, for example, for the Ara and Gal C1 peaks of the low-MW sample. 
${ }^{13} \mathrm{C}$ chemical shift (ppm)

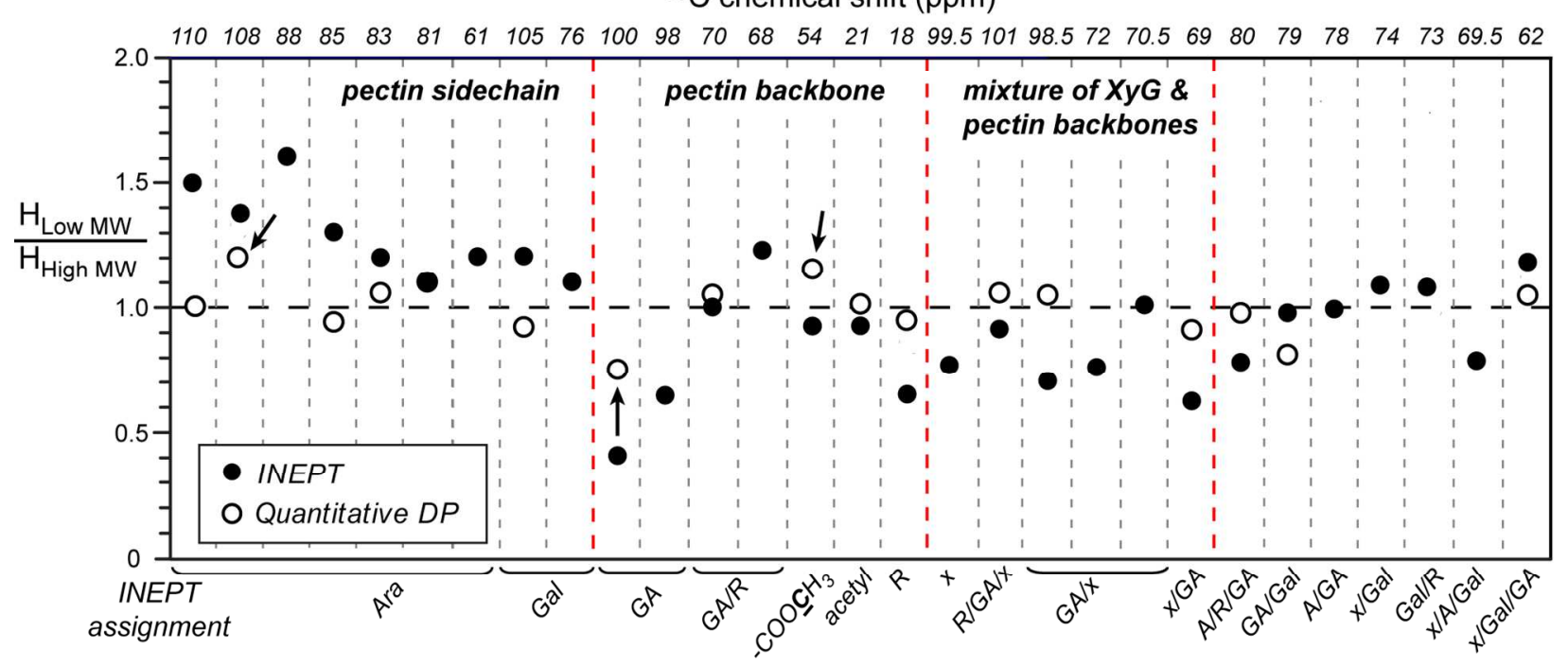

Figure 2. Quantitative and INEPT ${ }^{13} \mathrm{C}$ intensity ratios between the low-MW and high-MW cell walls. The peak heights of the low-MW spectrum are scaled by 0.64 to account for sample amount differences with the high-MW spectrum. Most quantitative intensity ratios are close to 1, except for sites indicated by arrows, while INEPT intensity ratios deviate more significant from 1, indicating significant differences in polysaccharide mobilities between the two cell walls. 


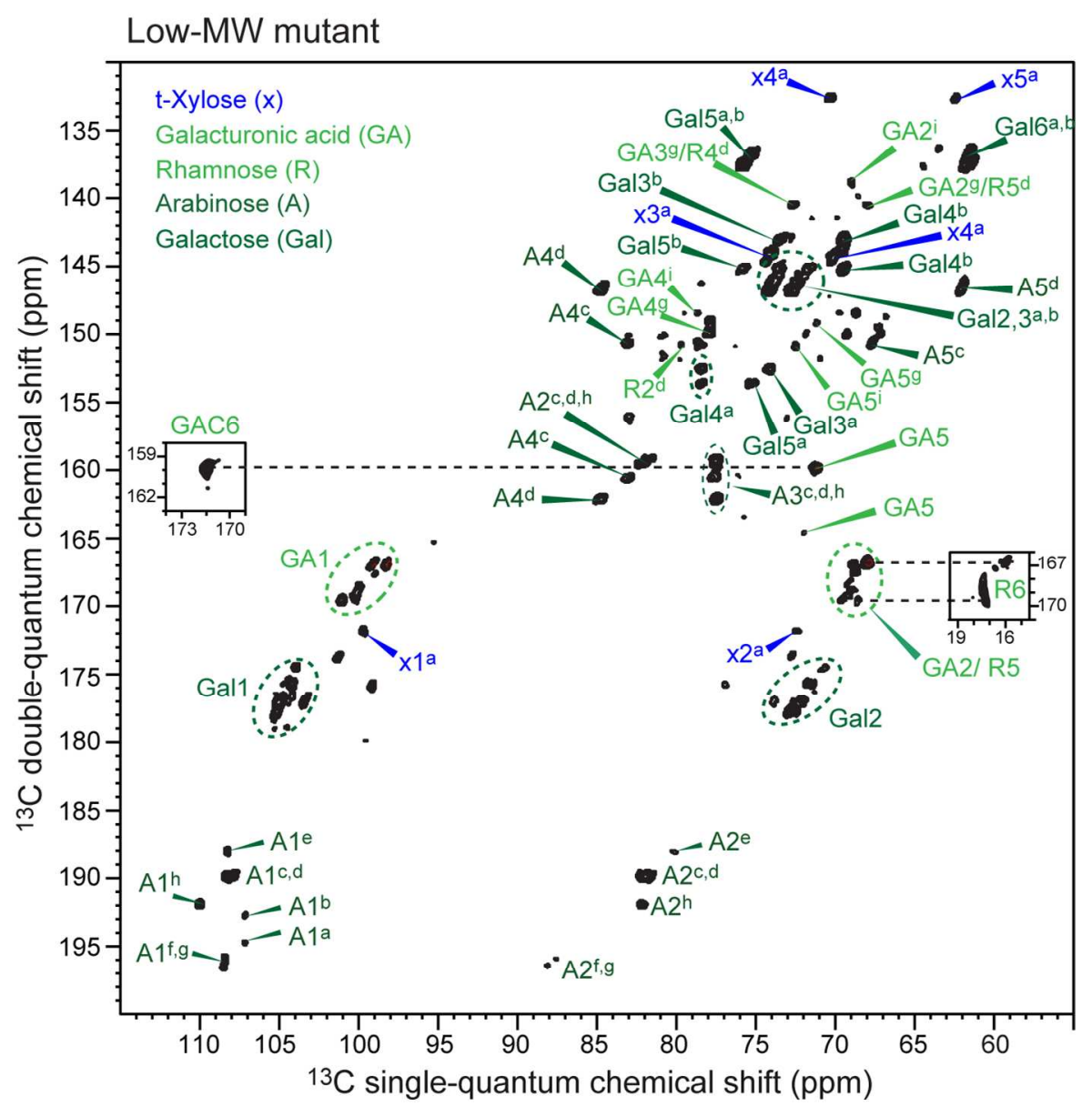

Figure 3. $2 \mathrm{D}{ }^{13} \mathrm{C}$ J-INADEQUATE spectrum of the low-MW cell wall. The spectrum was measured at $296 \mathrm{~K}$ under $12 \mathrm{kHz}$ MAS. Superscripts denote different subtypes of each monosaccharide. Boxed regions at double-quantum ${ }^{13} \mathrm{C}$ chemical shifts of $160 \mathrm{ppm}$ and $170 \mathrm{ppm}$ show the GalA C6 carbonyl signals and the Rha-C6 signals, respectively. 
A Low-MW mutant

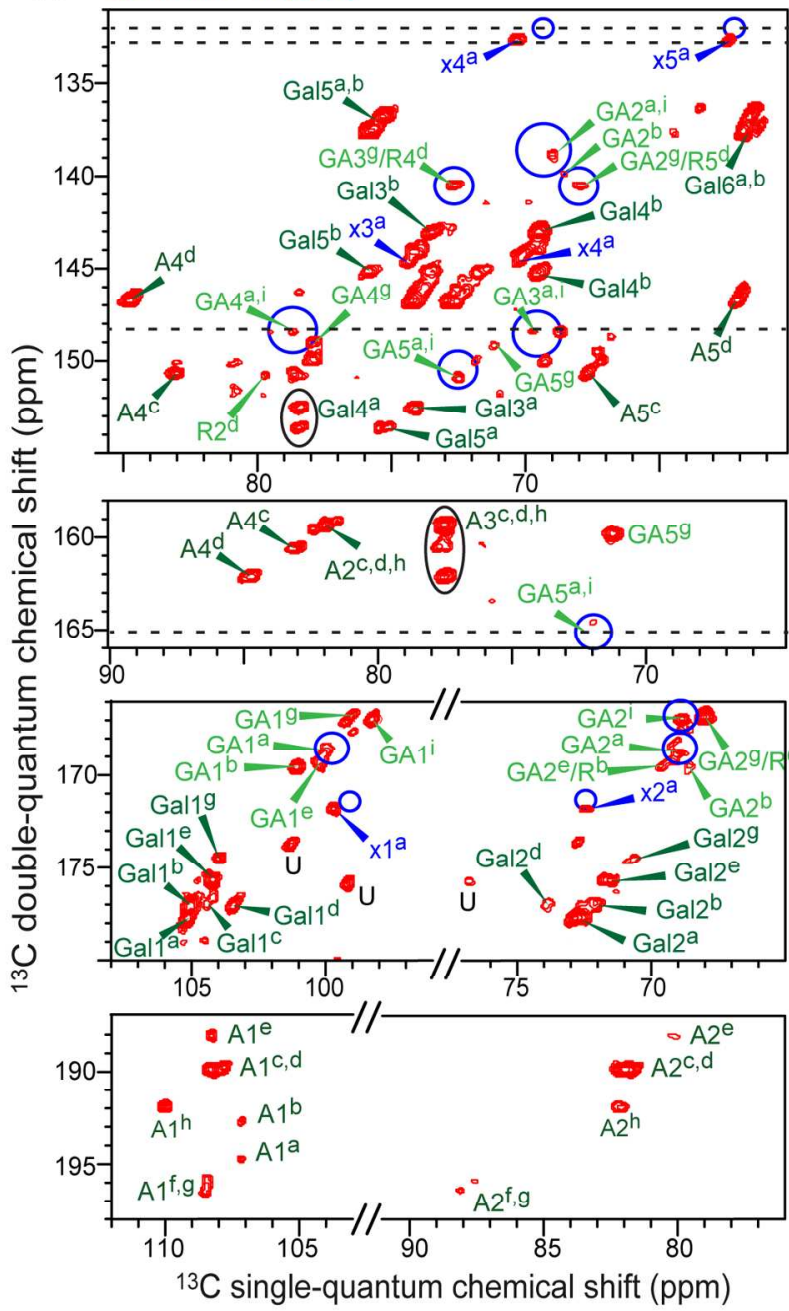

C $165 \mathrm{ppm}$

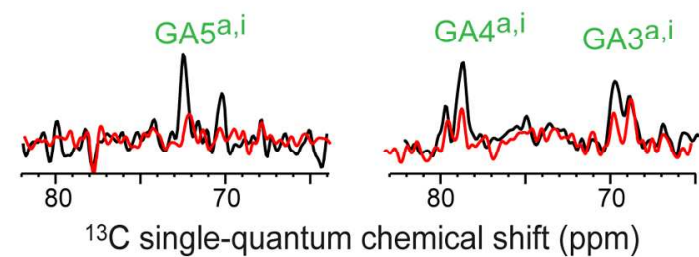

B High-MW mutant

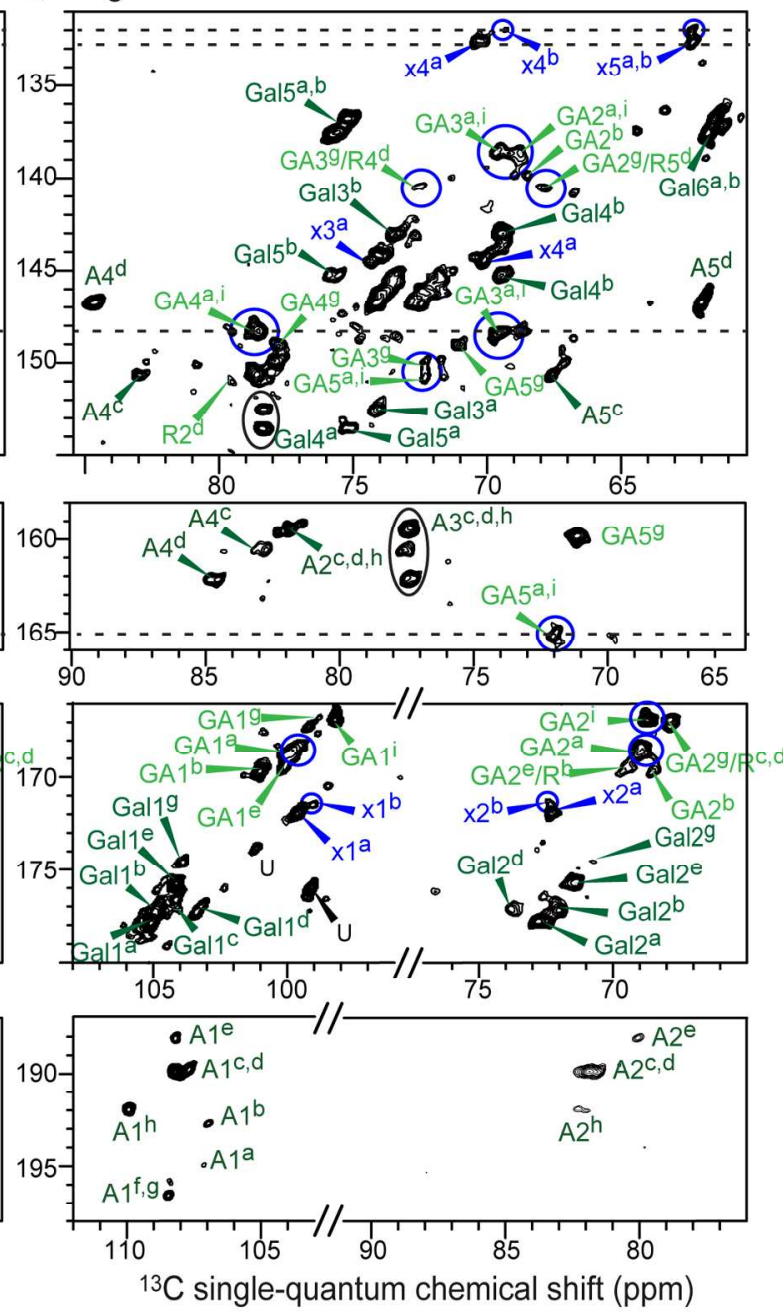

$133 \mathrm{ppm}$

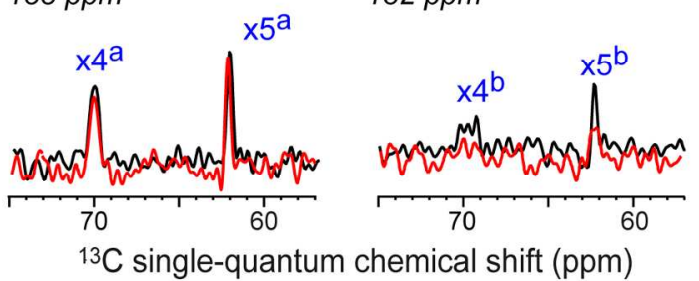

Figure 4. $2 \mathrm{D}{ }^{13} \mathrm{C}$ J-INADEQUATE spectra of the low-MW (A) and high-MW (B) cell walls. The letter "U" denotes peaks whose assignments are unknown. Based on the C1-C2 chemical shifts these peaks may be due to GalA, Rha or Xyl. Blue circles highlight regions of significant intensity differences. (C) Selected $1 \mathrm{D}{ }^{13} \mathrm{C}$ cross sections show intensity differences of matrix polysaccharide signals between the two cell walls. The intensities of Xyl-a and Xyl-b are reduced by $\sim 10 \%$ and $\sim 70 \%$ respectively, and the intensity of GalA-i is lower by $10-70 \%$ in the low-MW cell wall (red). The cross sections are plotted after multiplying the low-MW spectrum by 0.64 to account for sample amount differences. 
A Low-MW mutant

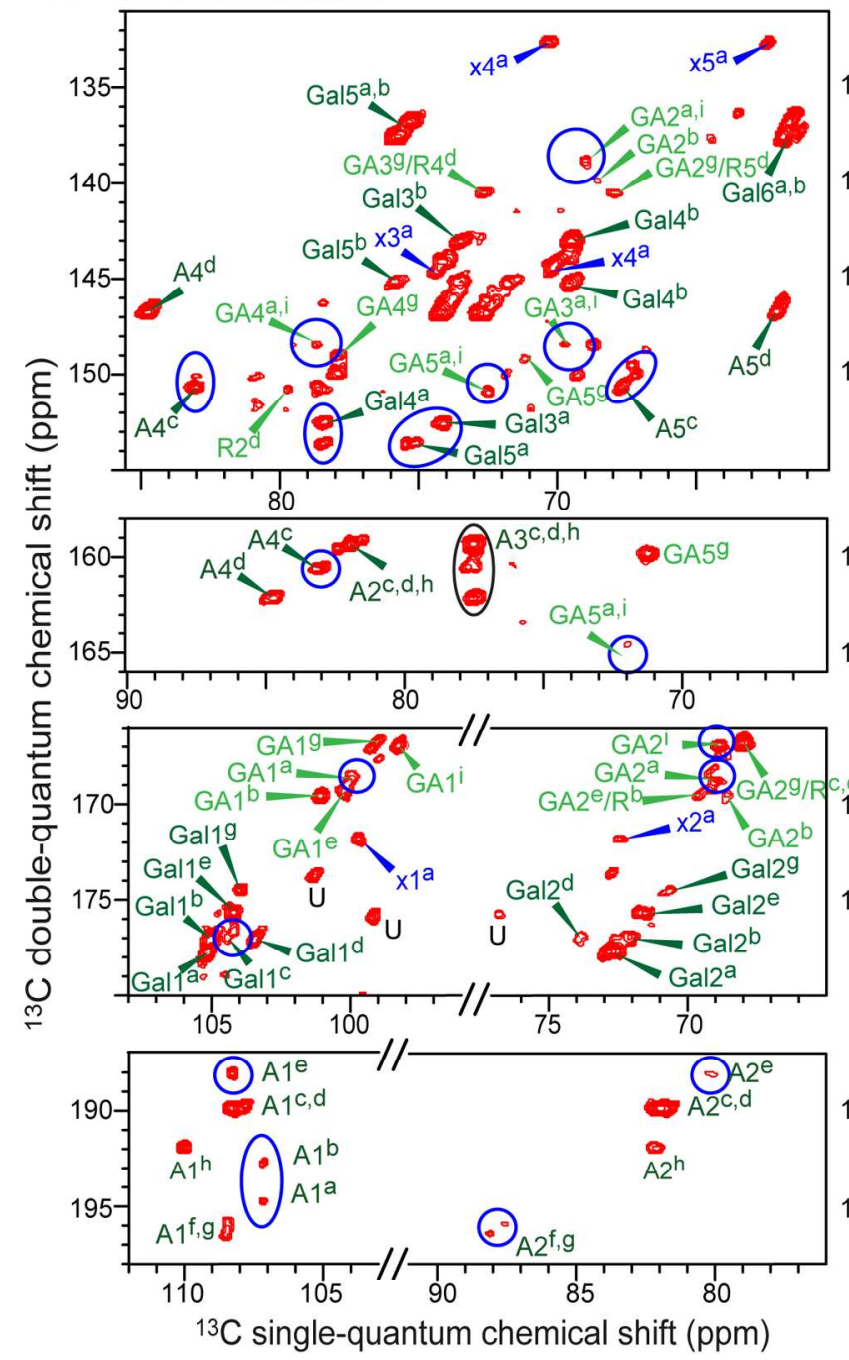

C $165 \mathrm{ppm}$

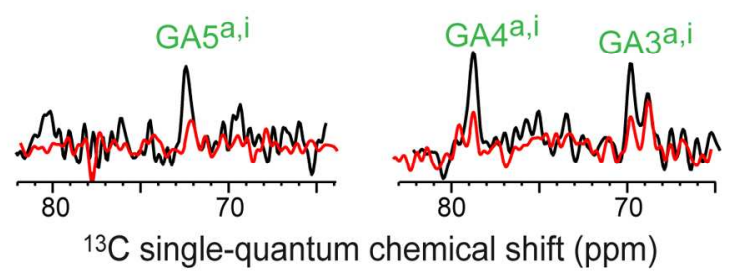

B Wild-type
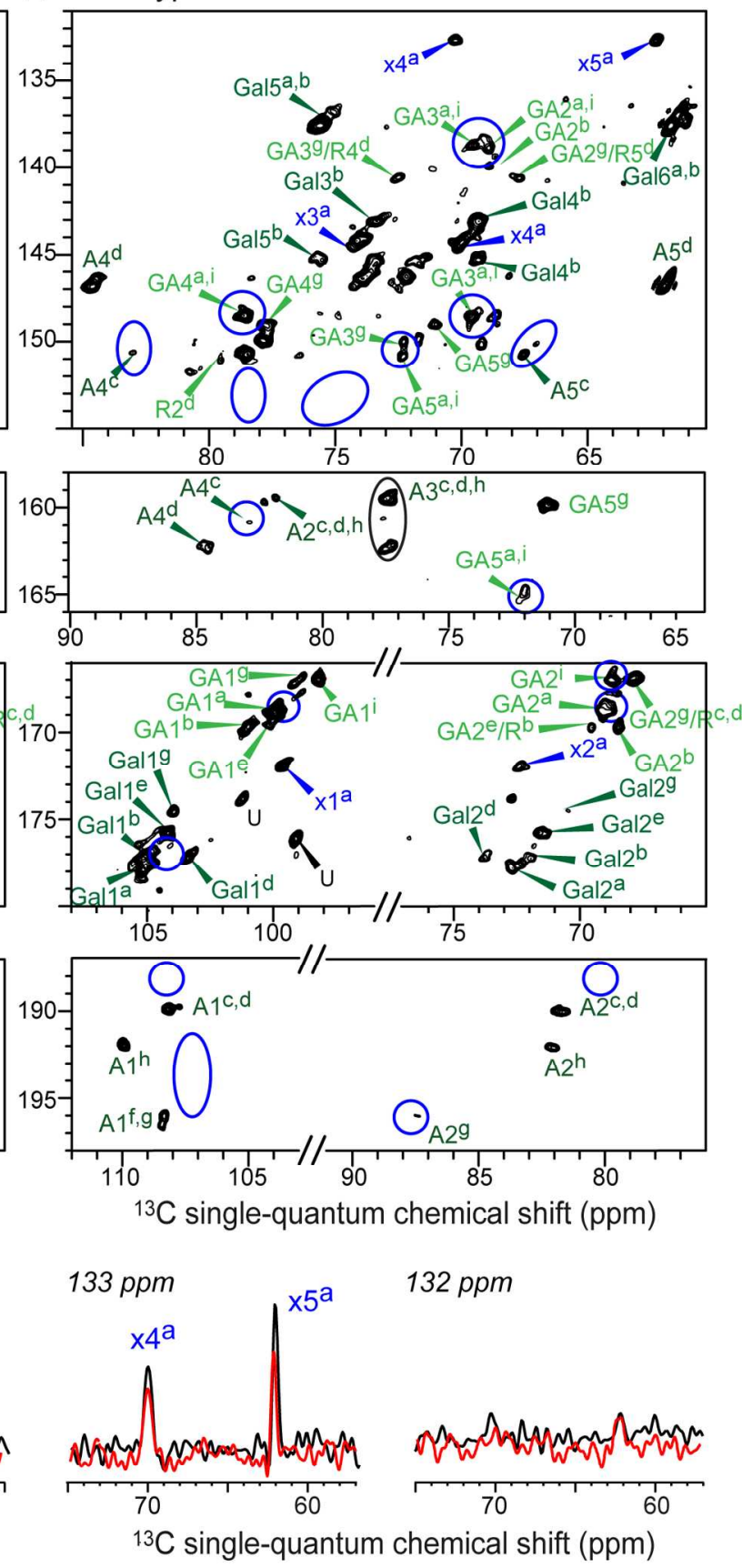

Figure 5. 2D ${ }^{13} \mathrm{C}$ J-INADEQUATE spectra of the low-MW (A) and wild-type (B) cell walls. Blue circles highlight regions of significant intensity differences. The letter "U" denotes peaks whose assignments are unknown. The low-MW sample shows weaker GalA-i and Xyl-b signals, and weaker or missing Ara-a,b,c,e,f and Gal-a sidechain signals. (C) Selected $1 \mathrm{D}{ }^{13} \mathrm{C}$ cross sections showing intensity differences for matrix polysaccharide signals between the two cell walls. The intensity of GalA-i is lower by $30-60 \%$ in the low-MW cell wall (red) and the 
intensity of Xyl-a is reduced by $\sim 30 \%$. The cross sections are plotted after multiplying the lowMW spectrum by 0.67 to account for sample amount differences.

1

2

3

4

5

6

7

8

9

10

11

12

13

14

15

16

17

18

19

20

21

22

23

24

25

26

27

28

29

30

31

32

33

34

35

36

37

38

39

40

41

42

43

44

45

46

47

48

49

50

51

52

53

54

55

56

57

58

59

60 
A Low-MW mutant

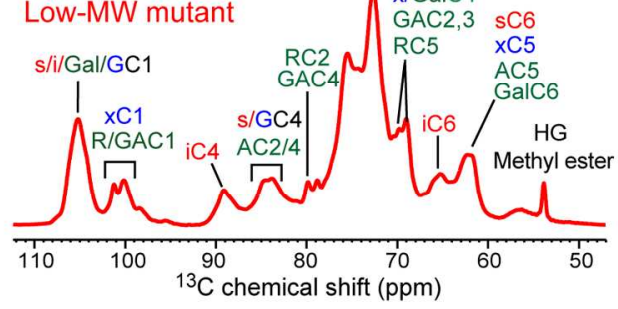

B Cellulose

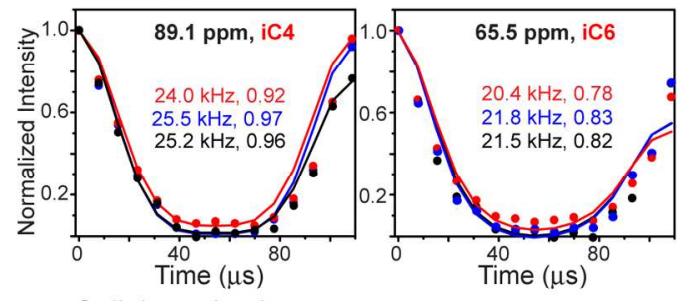

Cellulose-dominant

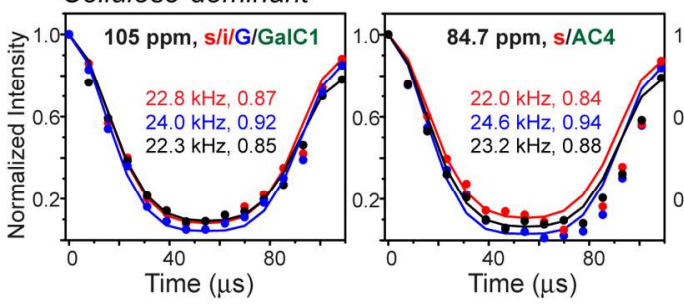

Matrix Polysaccharides

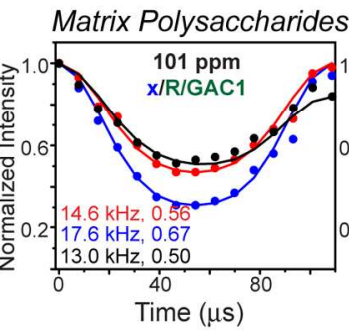

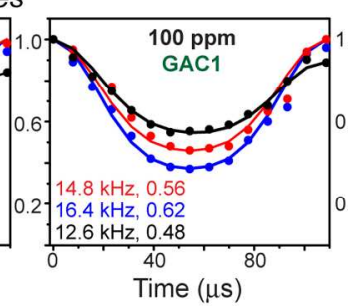
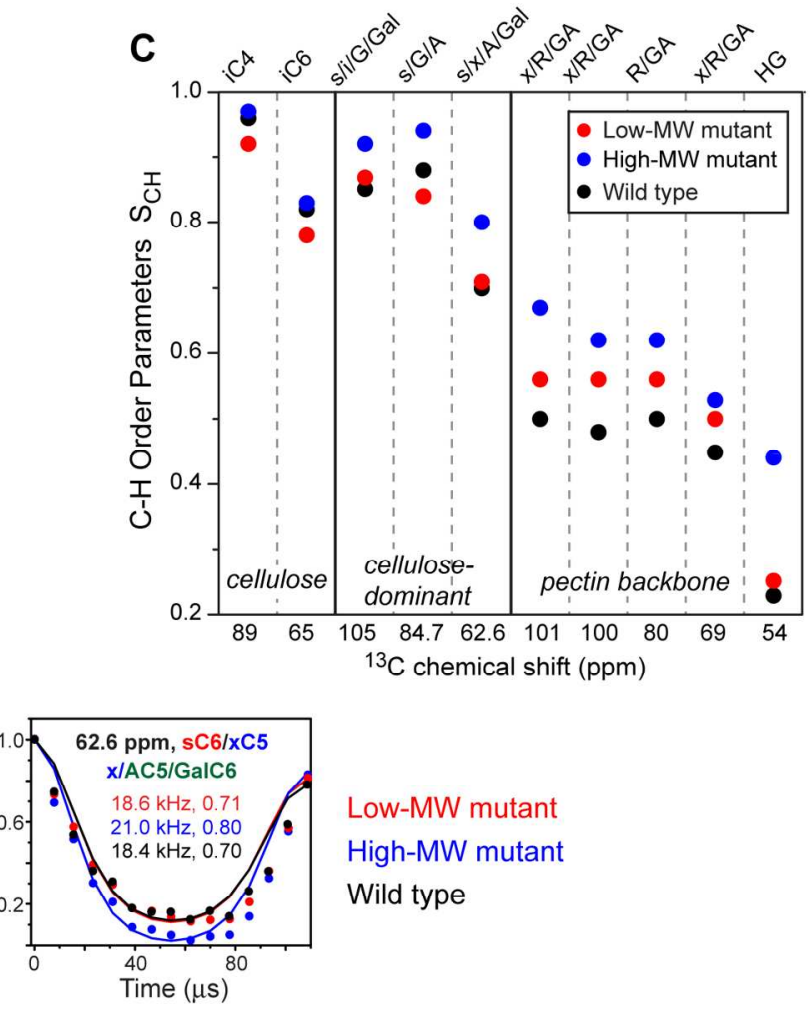

Low-MW mutant High-MW mutant Wild type

Figure 6. ${ }^{13} \mathrm{C}-{ }^{1} \mathrm{H}$ dipolar-doubled $\mathrm{CP}-\mathrm{DIPSHIFT}$ data of the low-MW (red), high-MW (blue), and wild-type Arabidopsis cell walls (black). (A) ${ }^{13} \mathrm{C} \mathrm{CP}$ spectrum of the low-MW mutant, showing various ${ }^{13} \mathrm{C}$ signals of interest. (B) ${ }^{13} \mathrm{C}-{ }^{1} \mathrm{H}$ dipolar dephasing curves of cellulose signals (top row), cellulose-dominant signals (middle row), and matrix polysaccharides signals (bottom row). The data were measured at $296 \mathrm{~K}$ under $9.2 \mathrm{kHz}$ MAS. Each panel in (B) gives the best-fit dipolar couplings $(\mathrm{kHz})$ after taking into account the FSLG scaling factor of 0.577 . The order parameters $\mathrm{S}_{\mathrm{CH}}$ are also given. (C) $\mathrm{C}-\mathrm{H}$ dipolar order parameters. The high-MW cell wall is more immobilized than the low-MW cell wall. The difference is the largest for the 101-ppm R/GA C1 signal, the 62.6-ppm s/x/A/Gal signal, and the 54-ppm methyl ester signal. 


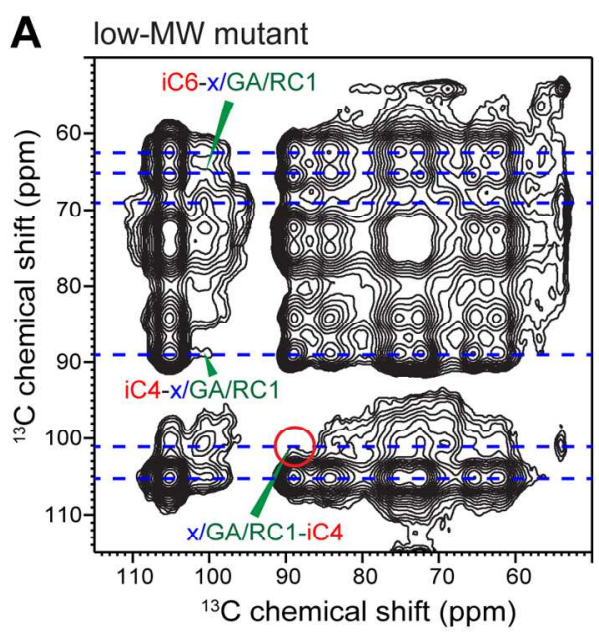

Cow-MW Mutant
high-MW Mutant

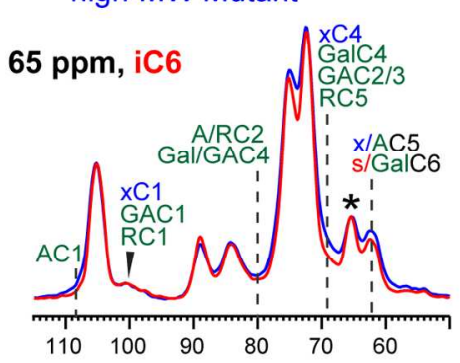

101 ppm,
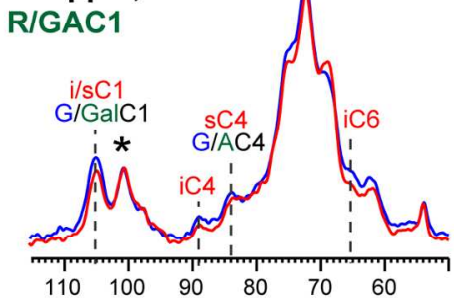

105 ppm, i/s/G/GalC1

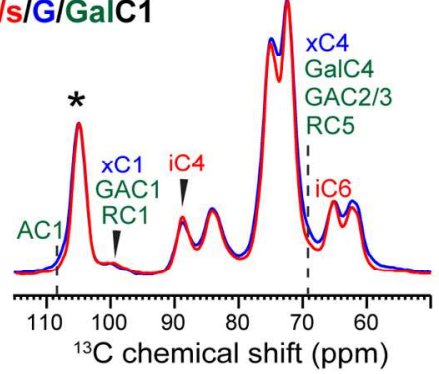

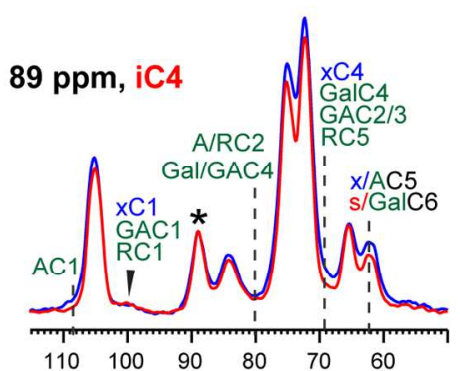

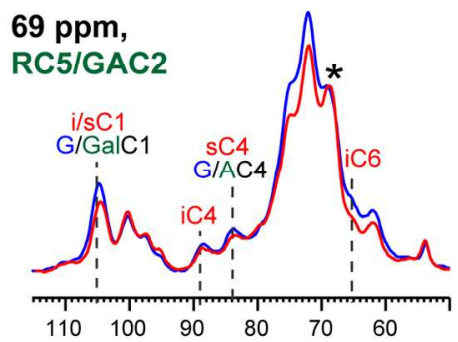

$62.4 \mathrm{ppm}$, x/AC5/s/GalC6

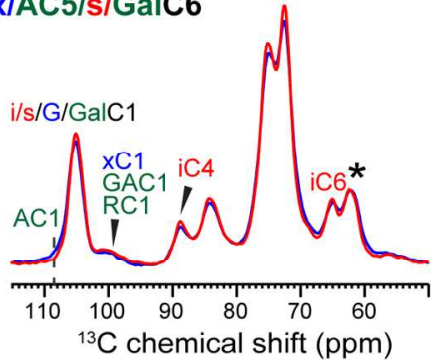

Figure 7. $2 \mathrm{D}{ }^{13} \mathrm{C}$ PDSD spectra of the (A) low-MW mutant and (B) high-MW mutant to detect intermolecular cross peaks. The spectra were measured at $253 \mathrm{~K}$ under $10 \mathrm{kHz}$ MAS using a 1.5 s spin diffusion mixing time. (C) Selected $1 \mathrm{D}{ }^{13} \mathrm{C}$ cross sections normalized by the diagonal peaks (asterisks). Dashed lines indicate pectin-cellulose cross peaks of interest. 
A High molecular-weight mutant

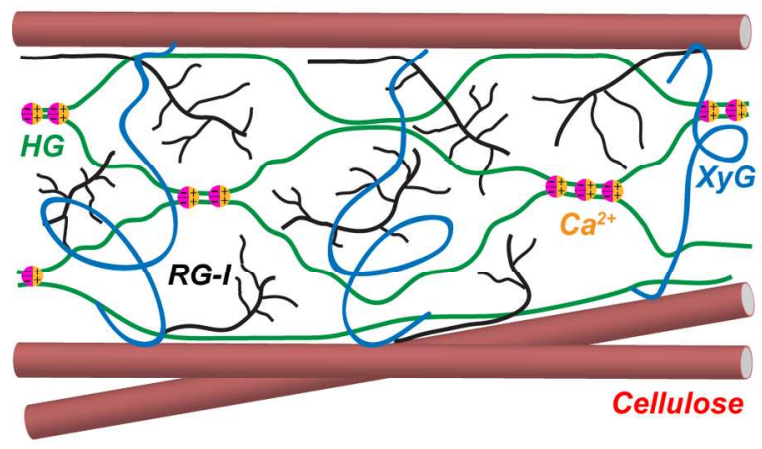

B Low molecular-weight mutant

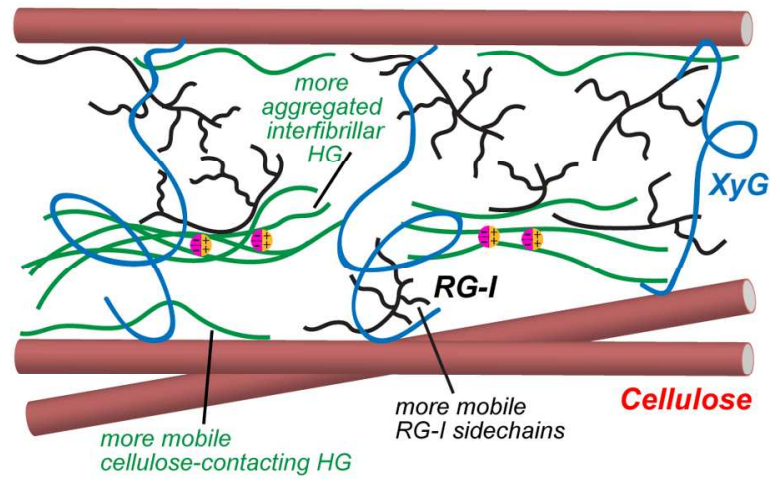

Figure 8. Models of the different polysaccharide dynamics and interactions in the (A) high-MW mutant cell wall and (B) the low-MW mutant cell wall. In both cell walls, HG (green) and RG-I (black) have a rigid cellulose-proximal domain and a mobile interfibrillar domain. The low-MW mutant shows more dynamic pectins near the cellulose microfibril (red) but more rigid interfibrillar HG and RG backbones, suggesting aggregation due to less calcium crosslinking. The RG-I sidechains are more mobile in the low-MW cell wall. These differences correlate with enhanced growth of the low-MW mutant. 


\section{References}

1. Jarvis, M. C., Cellulose Biosynthesis: Counting the Chains. Plant Physiol. 2013, 163, 1485-1486.

2. Nishiyama, Y.; Langan, P.; Chanzy, H., Crystal structure and hydrogen-bonding system in cellulose $\mathrm{I}_{\mathrm{b}}$ from synchrotron $\mathrm{X}$-ray and neutron fiber diffraction. J. Am. Chem. Soc. 2002, 124, 9074-9082.

3. Scheller, H. V.; Ulvskov, P., Hemicelluloses. Annu. Rev. Plant Biol. 2010, 61, 263-289.

4. Vogel, J., Unique aspects of the grass cell wall. Curr. Opin. Plant Biol. 2008, 11, 301307.

5. Carpita, N. C., Structure and biogenesis of the cell walls of grasses. Annu. Rev. Plant Phys. 1996, 47, 445-476.

6. Carpita, N. C.; Gibeaut, D. M., Structural models of primary cell walls in flowering plants: consistency of molecular structure with the physical properties of the walls during growth. Plant J. 1993, 3, 1-30.

7. Cosgrove, D. J., Re-constructing our models of cellulose and primary cell wall assembly. Curr. Opin. Plant Biol. 2014, 22C, 122-131.

8. Anderson, C. T., We be jammin': an update on pectin biosynthesis, trafficking and dynamics. J. Exp. Bot. 2016, 67, 495-502.

9. Mohnen, D., Pectin structure and biosynthesis. Curr. Opin. Plant Biol. 2008, 11, 266-277.

10. Levesque-Tremblay, G.; Pelloux, J.; Braybrook, S. A.; Muller, K., Tuning of pectin methylesterification: consequences for cell wall biomechanics and development. Planta 2015, $242,791-811$.

11. Boyer, J. S., Enzyme-Less Growth in Chara and Terrestrial Plants. Front Plant Sci 2016, 7,866 .

12. Derbyshire, P.; McCann, M. C.; Roberts, K., Restricted cell elongation in Arabidopsis hypocotyls is associated with a reduced average pectin esterification level. BMC Plant Biol. 2007, 7,31 .

13. Peaucelle, A.; Braybrook, S. A.; Le Guillou, L.; Bron, E.; Kuhlemeier, C.; Hofte, H., Pectin-Induced Changes in Cell Wall Mechanics Underlie Organ Initiation in Arabidopsis. Curr. Biol. 2011, 21, 1720-1726.

14. Caffall, K. H.; Mohnen, D., The structure, function, and biosynthesis of plant cell wall pectic polysaccharides. Carbohydr. Res. 2009, 344, 1879-1900.

15. Schols, H. A.; Voragen, A. G. J., Hairy (Ramified) Regions of Pectins .4. Occurrence of Pectic Hairy Regions in Various Plant-Cell Wall Materials and Their Degradability by Rhamnogalacturonase. Carbohydr. Res. 1994, 256, 83-95. 
16. Zykwinska, A. W.; Ralet, M. C. J.; Garnier, C. D.; Thibault, J. F. J., Evidence for in vitro binding of pectin side chains to cellulose. Plant Physiol. 2005, 139, 397-407.

17. Cosgrove, D. J., Growth of the plant cell wall. Nat. Rev. Mol. Cell Biol. 2005, 6, 850-861.

18. Cosgrove, D. J., Wall structure and wall loosening. A look backwards and forwards. Plant Physiol. 2001, 125, 131-134.

19. Park, Y. B.; Cosgrove, D. J., Xyloglucan and its interactions with other components of the growing cell wall. Plant Cell Physiol. 2015, 56, 180-194.

20. Park, Y. B.; Cosgrove, D. J., Changes in cell wall biomechanical properties in the xyloglucan-deficient xxt1/xxt2 mutant of arabidopsis. Plant Physiol. 2012a, 158, 465-475.

21. Park, Y. B.; Cosgrove, D. J., A revised architecture of primary cell walls based on biomechanical changes induced by substrate-specific endoglucanases. Plant Physiol. 2012b, 158, 1933-1943.

22. Dick-Perez, M.; Zhang, Y. A.; Hayes, J.; Salazar, A.; Zabotina, O. A.; Hong, M., Structure and interactions of plant cell wall polysaccharides by two- and three-dimensional magic-angle-spinning solid-state NMR. Biochemistry 2011, 50, 989-1000.

23. Wang, T.; Park, Y. B.; Caporini, M. A.; Rosay, M.; Zhong, L. H.; Cosgrove, D. J.; Hong, M., Sensitivity-enhanced solid-state NMR detection of expansin's target in plant cell walls. Proc. Natl. Acad. Sci. U.S.A. 2013, 110, 16444-16449.

24. Xiao, C.; Zhang, T.; Zheng, Y.; Cosgrove, D. J.; Anderson, C. T., Xyloglucan Deficiency Disrupts Microtubule Stability and Cellulose Biosynthesis in Arabidopsis, Altering Cell Growth and Morphogenesis. Plant Physiol. 2016, 170, 234-249.

25. Wang, T.; Phyo, P.; Hong, M., Multidimensional solid-state NMR spectroscopy of plant cell walls. Solid State Nucl. Magn. Reson. 2016, 78, 56-63.

26. Wang, T.; Hong, M., Solid-state NMR investigations of cellulose structure and interactions with matrix polysaccharides in plant primary cell walls. J. Exp. Bot. 2016, 67, 503514.

27. Wang, T.; Salazar, A.; Zabotina, O. A.; Hong, M., Structure and dynamics of Brachypodium primary cell wall polysaccharides from two-dimensional ${ }^{13} \mathrm{C}$ solid-state nuclear magnetic resonance spectroscopy. Biochemistry 2014, 53, 2840-2854.

28. Wang, T.; Park, Y. B.; Cosgrove, D. J.; Hong, M., Cellulose-Pectin Spatial Contacts Are Inherent to Never-Dried Arabidopsis thaliana Primary Cell Walls: Evidence from Solid-State NMR. Plant Physiol. 2015, 168, 871.

29. Wang, T.; Williams, J. K.; Schmidt-Rohr, K.; Hong, M., Relaxation-compensated difference spin diffusion NMR for detecting ${ }^{13} \mathrm{C}-{ }^{13} \mathrm{C}$ long-range correlations in proteins and polysaccharides. J. Biomol. NMR 2015, 61, 97-107. 
30. White, P. B.; Wang, T.; Park, Y. B.; Cosgrove, D. J.; Hong, M., Water-polysaccharide interactions in the primary cell wall of Arabidopsis thaliana from polarization transfer solid-state NMR. J. Am. Chem. Soc. 2014, 136, 10399-10409.

31. Cosgrove, D. J., Plant cell wall extensibility: connecting plant cell growth with cell wall structure, mechanics, and the action of wall-modifying enzymes. J. Exp. Bot. 2016, 67, 463-476.

32. Whitney, S. E. C.; Brigham, J. E.; Darke, A. H.; Reid, J. S. G.; Gidley, M. J., In-Vitro Assembly of Cellulose/Xyloglucan Networks - Ultrastructural and Molecular Aspects. Plant J. 1995, 8, 491-504.

33. Pauly, M.; Albersheim, P.; Darvill, A.; York, W. S., Molecular domains of the cellulose/xyloglucan network in the cell walls of higher plants. Plant J. 1999, 20, 629-639.

34. Chanliaud, E.; De Silva, J.; Strongitharm, B.; Jeronimidis, G.; Gidley, M. J., Mechanical effects of plant cell wall enzymes on cellulose/xyloglucan composites. Plant J. 2004, 38, 27-37.

35. Chanliaud, E.; Gidley, M. J., In vitro synthesis and properties of pectin/Acetobacter xylinus cellulose composites. Plant J. 1999, 20, 25-35.

36. Zykwinska, A.; Thibault, J. F.; Ralet, M. C., Competitive binding of pectin and xyloglucan with primary cell wall cellulose. Carbohydr. Polymers 2008, 74, 957-961.

37. Lopez-Sanchez, P.; Martinez-Sanz, M.; Bonilla, M. R.; Wang, D.; Gilbert, E. P.; Stokes, J. R.; Gidley, M. J., Cellulose-pectin composite hydrogels: Intermolecular interactions and material properties depend on order of assembly. Carbohydr. Polym. 2017, 162, 71-81.

38. Lopez-Sanchez, P.; Martinez-Sanz, M.; Bonilla, M. R.; Wang, D.; Walsh, C. T.; Gilbert, E. P.; Stokes, J. R.; Gidley, M. J., Pectin impacts cellulose fibre architecture and hydrogel mechanics in the absence of calcium. Carbohydr. Polym. 2016, 153, 236-245.

39. Harris, D. M.; Corbin, K.; Wang, T.; Gutierrez, R.; Bertolo, A. L.; Petti, C.; Smilgies, D. M.; Estevez, J. M.; Bonetta, D.; Urbanowicz, B. R.; Ehrhardt, D. W.; Somerville, C. R.; Rose, J. K. C.; Hong, M.; DeBolt, S., Cellulose microfibril crystallinity is reduced by mutating Cterminal transmembrane region residues CESA ${ }^{\mathrm{A} 903 \mathrm{~V}}$ and CESA3 ${ }^{\mathrm{T} 942 \mathrm{I}}$ of cellulose synthase. Proc. Natl. Acad. Sci. U.S.A. 2012, 109, 4098-4103.

40. Cavalier, D. M.; Lerouxel, O.; Neumetzler, L.; Yamauchi, K.; Reinecke, A.; Freshour, G.; Zabotina, O. A.; Hahn, M. G.; Burgert, I.; Pauly, M.; Raikhel, N. V.; Keegstra, K., Disrupting Two Arabidopsis thaliana Xylosyltransferase Genes Results in Plants Deficient in Xyloglucan, a Major Primary Cell Wall Component. Plant Cell 2008, 20, 1519-1537.

41. Simmons, T. J.; Mortimer, J. C.; Bernardinelli, O. D.; Poppler, A. C.; Brown, S. P.; Deazevedo, E. R.; Dupree, R.; Dupree, P., Folding of xylan onto cellulose fibrils in plant cell walls revealed by solid-state NMR. Nat. Commun. $2016,7$.

42. Dupree, R.; Simmons, T. J.; Mortimer, J. C.; Patel, D.; Iuga, D.; Brown, S. P.; Dupree, P., Probing the Molecular Architecture of Arabidopsis thaliana Secondary Cell Walls Using Twoand Three-Dimensional ${ }^{13} \mathrm{C}$ Solid State Nuclear Magnetic Resonance Spectroscopy.

Biochemistry 2015, 54, 2335-2345. 
43. Xiao, C.; Somerville, C.; Anderson, C. T., POLYGALACTURONASE INVOLVED IN EXPANSION1 functions in cell elongation and flower development in Arabidopsis. Plant Cell 2014, 26, 1018-1035.

44. Mouille, G.; Ralet, M. C.; Cavelier, C.; Eland, C.; Effroy, D.; Hematy, K.; McCartney, L.; Truong, H. N.; Gaudon, V.; Thibault, J. F.; Marchant, A.; Hofte, H., Homogalacturonan synthesis in Arabidopsis thaliana requires a Golgi-localized protein with a putative methyltransferase domain. Plant Journal 2007, 50, 605-614.

45. Krupkova, E.; Immerzeel, P.; Pauly, M.; Schmulling, T., The TUMOROUS SHOOT DEVELOPMENT2 gene of Arabidopsis encoding a putative methyltransferase is required for cell adhesion and co-ordinated plant development. The Plant journal : for cell and molecular biology 2007, 50, 735-750.

46. Kim, S. J.; Held, M. A.; Zemelis, S.; Wilkerson, C.; Brandizzi, F., CGR2 and CGR3 have critical overlapping roles in pectin methylesterification and plant growth in Arabidopsis thaliana. Plant J 2015, 82, 208-220.

47. Caffall, K. H.; Pattathil, S.; Phillips, S. E.; Hahn, M. G.; Mohnen, D., Arabidopsis thaliana T-DNA mutants implicate GAUT genes in the biosynthesis of pectin and xylan in cell walls and seed testa. Mol Plant 2009, 2, 1000-1014.

48. Kong, Y.; Zhou, G.; Yin, Y.; Xu, Y.; Pattathil, S.; Hahn, M. G., Molecular analysis of a family of Arabidopsis genes related to galacturonosyltransferases. Plant physiology 2011, 155, 1791-1805.

49. Xiao, C.; Barnes, W. J.; Zamil, M. S.; Yi, H.; Puri, V. M.; Anderson, C. T., Activation tagging of Arabidopsis POLYGALACTURONASE INVOLVED IN EXPANSION2 promotes hypocotyl elongation, leaf expansion, stem lignification, mechanical stiffening, and lodging. Plant J 2017, 89, 1159-1173.

50. Elena, B.; Lesage, A.; Steuernagel, S.; Bockmann, A.; Emsley, L., Proton to carbon-13 INEPT in solid-state NMR spectroscopy. J. Am. Chem. Soc. 2005, 127, 17296-17302.

51. Yu, B. W.; van Ingen, H.; Vivekanandan, S.; Rademacher, C.; Norris, S. E.; Freedberg, D. I., More accurate (1) $\mathrm{J}(\mathrm{CH})$ coupling measurement in the presence of (3) $\mathrm{J}(\mathrm{HH})$ strong coupling in natural abundance. J. Magn. Reson. 2012, 215, 10-22.

52. Cadars, S.; Sein, J.; Duma, L.; Lesage, A.; Pham, T. N.; Baltisberger, J. H.; Brown, S. P.; Emsley, L., The refocused INADEQUATE MAS NMR experiment in multiple spin-systems: Interpreting observed correlation peaks and optimising lineshapes. J. Magn. Reson. 2007, 188, 24-34.

53. Lesage, A.; Auger, C.; Caldarelli, S.; Emsley, L., Determination of through-bond carboncarbon connectivities in solid-state NMR using the INADEQUATE experiment. J. Am. Chem. Soc. 1997, 119, 7867-7868.

54. Munowitz, M. G.; Griffin, R. G.; Bodenhausen, G.; Huang, T. H., Two-Dimensional Rotational Spin-Echo Nuclear Magnetic-Resonance in Solids - Correlation of Chemical-Shift and Dipolar Interactions. J. Am. Chem. Soc. 1981, 103, 2529-2533. 
55. Hong, M.; Gross, J. D.; Rienstra, C. M.; Griffin, R. G.; Kumashiro, K. K.; Schmidt-Rohr, K., Coupling amplification in 2D MAS NMR and its application to torsion angle determination in peptides. J. Magn. Reson. 1997, 129, 85-92.

56. Bielecki, A.; Kolbert, A. C.; Levitt, M. H., Frequency-Switched Pulse Sequences Homonuclear Decoupling and Dilute Spin NMR in Solids. Chem. Phys. Lett. 1989, 155, 341-346.

57. Rienstra, C. M.; Tucker-Kellogg, L.; Jaroniec, C. P.; Hohwy, M.; Reif, B.; McMahon, M. T.; Tidor, B.; Lozano-Perez, T.; Griffin, R. G., De novo determination of peptide structure with solid-state magic-angle spinning NMR spectroscopy. Proc. Natl. Acad. Sci. USA 2002, 99, 10260-10265.

58. Hong, M.; Griffin, R. G., Resonance Assignment for Solid Peptides by Dipolar-Mediated 13C/15N Correlation Solid-State NMR. J. Am. Chem. Soc. 1998, 120, 7113-7114.

59. Hediger, S.; Emsley, L.; Fischer, M., Solid-state NMR characterization of hydration effects on polymer mobility in onion cell-wall material. Carbohydr. Res. 1999, 322, 102-112.

60. Wang, T.; Zabotina, O.; Hong, M., Pectin-cellulose interactions in the Arabidopsis primary cell wall from two-dimensional magic-angle-spinning solid-state nuclear magnetic resonance. Biochemistry 2012, 51, 9846-9856.

61. Zhao, Q.; Yuan, S.; Wang, X.; Zhang, Y.; Zhu, H.; Lu, C., Restoration of mature etiolated cucumber hypocotyl cell wall susceptibility to expansin by pretreatment with fungal pectinases and EGTA in vitro. Plant Physiol 2008, 147, 1874-1885.

62. Ferrari, S.; Savatin, D. V.; Sicilia, F.; Gramegna, G.; Cervone, F.; Lorenzo, G. D., Oligogalacturonides: plant damage-associated molecular patterns and regulators of growth and development. Front Plant Sci 2013, 4, 49.

63. Peaucelle, A.; Braybrook, S.; Hofte, H., Cell wall mechanics and growth control in plants: the role of pectins revisited. Front. Plant Sci. 2012, 3.

64. Hamann, T., Plant cell wall integrity maintenance as an essential component of biotic stress response mechanisms. Frontiers in plant science 2012, 3, 77.

65. Ogawa, M.; Kay, P.; Wilson, S.; Swain, S. M., ARABIDOPSIS DEHISCENCE ZONE POLYGALACTURONASE1 (ADPG1), ADPG2, and QUARTET2 are Polygalacturonases required for cell separation during reproductive development in Arabidopsis. Plant Cell 2009, 21, 216-233.

66. Peaucelle, A.; Wightman, R.; Höfte, H., The Control of Growth Symmetry Breaking in the Arabidopsis Hypocotyl. Current Biology 2015, 25, 1746-1752. 


\section{Page 39 of 39}

1

2

3

4

5

6

7

8

9

10

11

12

13

14

15

16

17

18

19

20

21

22

23

24

25

26

27

28

29

30

31

32

33

34

35

36

37

38

39

40

41

42

43

44

45

46

47

48

49

50

51

52

53

54

55

56

57

58

59

60

Table of Content Graphic

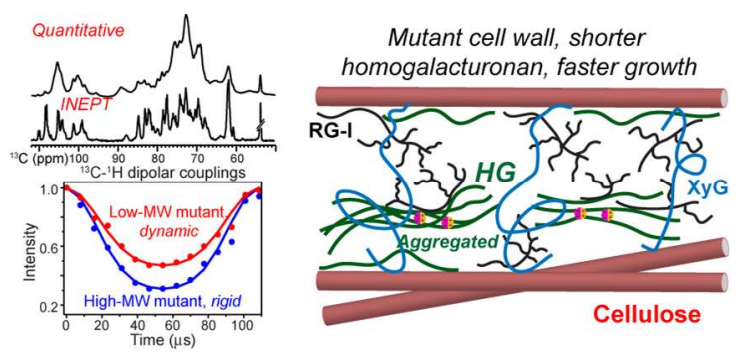

